\title{
Morbi-Mortalidad, Clasificación y Tratamiento del Aborto Séptico
}

\author{
Dres.: Armando Lozano C.* \\ María Teresa Peralta A.** \\ Fabio Reyes M.*** \\ Jaime Saravia $* * * *$
}

\section{INTRODUCCION}

El aborto séptico continúa siendo un problema grave en los servicios de obstetricia por ser la primera causa de mortalidad materna, por consumir un alto porcentaje del presupuesto de las instituciones destinadas a la atención materno-infantil, por carecerse de criterio unificado para su tratamiento, por expresar una situación socioeconómica y cultural que se aprecia en forma alarmante en nuestras instituciones de asistencia pública, donde se atienden principalmente mujeres de sectores marginados de la producción, desprotegidas por la segúridad social y con ingresos inferiores al salario mínimo, que implican desnutrición, hacinamiento e ignorancia, factores estos importantes en la gravedad de la infección.

Con el objeto de contribuir a la solución de este problema y colaborar al relato oficial del XIII Congreso Nacional de la especialidad "Aborto en Colombia", presentamos: 1.) Una revisión de 9 años comprendidos entre 1970 a 1978. 2.) Una nueva clasificación del aborto séptico por estados, según la extensión y gravedad de la sepsis; además el tratamiento específico para cada uno de ellos. 3.) Un estudio microbio-

\footnotetext{
* Prof. asist. obstetricia F. Med. U. Nal.

** Med. hospitalario obst.

*** R III Ginecobstetricia

**** Prof. Ásoc. F. Med. U. Nal

***** Prof. As. Med. Int. F. M. U. N.
}

lógico de la sepsis obstétrica. 4.) La clasificación clínica de los antibióticos y el criterio con que se manejan en el Servicio de Sépticas del IMI.

De los 9 años revisados se escogieron para el presente trabajo 188 casos de pacientes atendidas en el Servicio durante el año de 1977, con historias mejor elaboradas, informes de laboratorio y patología más completos, en los cuales hubo disponibilidad de drogas y recursos humanos apropiados.

Pretendemos dar bases que permitan lograr un criterio unificado nacional en el tratamiento del aborto séptico. con el objeto de hacer posteriormente una evaluación amplia del problema. Pruponemos esto con base en nuestra experiencia de 15 años en el Servicio de Sépticas del IMI de Bogotá, lapso en el cual se atendieron 5.250 pacientes, de las cuales murieron 986 .

Finalmente afirmamos no poder ofrecer solución definitiva al problema por cuanto el aspecto médico no es factor determinante y corresponde al Estado dar solución a los factores socioeconómicos y culturales que son la causa fundamental del aborto infectado.

Damos nuestros agradecimientos a la señora Dora de Hormaza, Jefe del Departamento de Estadística del IMI, al señor Rojas, empleado del mismo Dpto., y a todo el personal médico y paramédico que en una u otra forma contribuyeron en la ejecución de este trabajo. 
Queremos resaltar nuestra gratitud y respeto a las pacientes, quienes constituyen el motivo principal que nos impulsa a estudiar y trabajar con decisión y sacrificio.

\section{Planteamiento del problema}

El aborto séptico tiene implicaciones sociales graves, porque: a) es causa y consecuencia de inestabilidad familiar; b) en él se expresa la influencia del "machismo" que considera a la mujer como un ser inferior, instrumento de placer y descarga en ella toda la responsabilidad del embarazo y la crianza y c) es factor económico el principal motivo del aborto provocado.

En nuestro país el aborto se practica en condiciones sépticas a mujeres anémicas y desnutridas, causa determinante de la gravedad de la infección; sumado a esto hay falta de políticas de salud que impulsen no solamente la Medicina Curativa sino también la Preventiva.

Nos preguntamos si en condiciones de nutrición, vivienda y educación adecuadas, con reivindicación social de la mujer, con instituciones asistenciales que brinden una atención satisfactoria y con un mejor conocimiento médico teórico-práctico de la infección. podriamos disminuir notoriamente la morbi-mortalidad materna.

\section{MARCO TEORICO}

\section{Antecedentes de la investigación}

De acuerdo con el problema planteado, específicamente en lo relacionado a morbi-mortalidad materna y a falta de un criterio unificado para el manejo y tratamiento de las pacientes con aborto séptico, hemos encontrado estudios a nivel local, nacional e internacional, que muestran la alta tasa de mortalidad materna debida al aborto infectado y la responsabilidad que cabe a las instituciones asistenciales, al médico y al Estado.

Estudios realizados en el IMI muestran porcentajes de mortalidad materna por aborto séptico con variaciones que fluctúan entre el 16.6 al $59 \%$ notándose un aumento constante a partir de 1971 $(1,2,3)$ (Cuadro $N^{\circ}$ 1).

\section{CUADRO N $N 1$}

\section{IMI - Estudios de mortalidad por aborto infectado}

\begin{tabular}{lcc}
\hline \multicolumn{1}{c}{ Autor } & Año & Porcentaje \\
\hline Peralta Cayón & 1957 & 16.6 \\
Rojas & 1970 & 64.0 \\
Sánchez Torres & 1975 & 45.1 \\
\hline
\end{tabular}

En el plano nacional, la mortalidad por esta causa es de $42 \%$ en Medellín, $33.7 \%$ en Cali $(4,5)$ y $38 \%$ en Bogotá.

Estas variaciones no son significativas, a diferencia de lo observado por algunos autores en el campo internacional $(6,7,8)$ variaciones grandes, cuando comparan países desarrollados con aquellos de bajo desarrollo, como el nuestro (Cuadro № 2).

CUADRO N: 2

Mortalidad por aborto infectado en el plano americano

\begin{tabular}{lr}
\hline Estados Unidos & $1.7 \%$ \\
Cuba & $2.5 \%$ \\
Méjico & $57.5 \%$ \\
Colombia & $38.0 \%$ \\
\hline
\end{tabular}

\section{Bases teóricas}

La infección obstétrica se produce al perderse la barrera natural constituida por las mucosas, el moco cervical y las 
membranas ovulares, lo cual conlleva la contaminación del aparato genital por gérmenes potencialmente patógenos, que normalmente' se encuentran en la vagina; sumado a esto tenemos la baja de defensas por anemia, desnutrición, bloqueo relativo del retículo-endotelio por esteroides placentarios y presencia de restos ovulares como medio de cultivo; se produce el desequilibrio ecológico entre la flora saprofita, la patógena y el huésped, desencadenándose la infección $(9,10)$. Las condiciones anteriormente anotadas hacen que la sepsis obstétrica sea más grave que la que se produce en otro tipo de pacientes (11. 12).

Cuando los gérmenes infectantes penetran en los tejidos y participan de su metabolismo, el foco séptico se disemina por contigüidad produciendo miometritis, endosalpingitis y peritonitis; por vía hemática hace siembras a distancia y por vía linfática ocasiona celulitis pélvica y del infundíbulo $(13,14)$.

El organismo dispone solamente de la fagocitosis como mecanismo para liberarse de los gérmenes patógenos; el tratamiento médico tiene por objeto favorecerla mediante procedimientos $\mathrm{co}$ mo:

- Asepsia y antịsepsia

- Aplicación de sueros y vacunas

- Plasma, albúmina y complemento

- Hiperalimentación oral y parenteral

- Extirpación quirúrgica del foco séptico

- Empleo racional de los antibióticos (15).

\section{Microbiología}

La infección es producida por la flora potencialmente patógena que se encuentra en la vagina constituida principalmente por enterobacilos, estafilococos, pseudomonas, bacteroides y clos. tridium. Estos gérmenes generalmente se presentan asociados y actúan en el organismo ocasionando necrosis tisular y hemólisis.

Por otro lado, las toxinas elaboradas y las endotoxinas, provocan una res. puesta inmunológica exagerada que desencadena el "shock" séptico (16-21).

\section{Antibióticos}

Los antibióticos como sustancias de origen biológico actúan interfiriendo al metabolismo celular a nivel de sus diferentes estructuras, ocasionando fenómenos de bacteriostasis o bacteriolisis. que facilitan la fagocitosis (22); estas alteraciones metabólicas también las producen en las células orgánicas cuando actúan sobre estructuras similares y por esta razón tienen un efecto bloquea. dor de la fagocitosis (11).

Por otra parte destruyen flora saprofita antagónica de la flora patógena, lo cual conduce a la suprainfección como complicación yatrogénica por mal uso de los antibióticos (23).

\section{Hipótesis}

La alta tasa de mortalidad materna depende de la infección y puede ser modificada con un adecuado tratamiento.

\section{Sistema de variables}

Mortalidad materna: es la relación entre el número de pacientes embarazadas fallecidas, desde el comienzo de la gestación, hasta 90 días después del parto, sobre 10.000 nacidos vivos; en este trabajo es una variable dependiente.

Infección: es la invasión de un tejido orgánico por gérmenes patógenos que. inician un proceso de reproducción rápida, participando del metabolismo celular y ocasionando fenómenos de destrucción tisular. La tomamos como una variable independiente. 
Nutrición: es el estado normal de proteínas en un organismo; se mide en gramos de proteínas totales y se considera noraml de 6-8 g. Variable intervinente.

Microbiología: es el estudio etiológico de la infección. Variable independiente.

Antibióticos: sustancias de origen biológico que alteran el metabolismo celular a nivel de sus diferentes estructuras, produciendo fenómenos de bacteriostasis y bacteriolisis. Variable independiente.

Cirugía: en sepsis es el procedimiento que tiene por objeto extirpar el foco séptico. Variable independiente.

Complicaciones: nos referimos a la extensión del proceso séptico inicial por causa médica, quirúrgica o del mismo cuadro infeccioso. Variable intervinente.

Edad, paridad y semanas de gestación las consideramos como variables intervinentes.

\section{METODOLOGIA}

El presente trabajo se realizó en el Servicio de Sépticas del IMI de Bogotá, el cual cuenta con el siguiente personal: Jefe del Servicio, un Especialista, un Residente Rotatorio de último año, un Interno Rotatorio, una Religiosa que desempeña las funciones de Enfermera Jefe, 17 Auxiliares de Enfermería distribuidas en 4 turnos y un Camillero.

La planta física está constituida por dos salones con 18 camas, un cuarto de examen y dos salas de cirugía (para intervenciones y drenajes de abscesos mamarios o de glándula de Bartholín).

En el servicio se atienden no sólo pacientes de aborto séptico, sino también puérperas y cirugías ginecológicas y obstétricas infectadas.

Se revisaron 3.140 historias clínicas de pacientes atendidas en un período de 9 años, comprendido entre 1970 y 1978 y se seleccionaron 330 casos manejados en 1977 por ser el más representativo del universo en estudio; de las 330 pacientes, 188 corresponden a infección por aborto provocado.

Se analizan edad, paridad, semanas de gestación, maniobras abortivas, estado nutricional, clasificación clínica del aborto, laboratorio clínico y patología; antibióticos, tratamiento quirúrgico, complicaciones y mortalidad.

\section{Tipo de investigación}

Aplicada: se propone dar solución a problemas prácticos.

Descriptiva: muestra la importancia del problema de la sepsis y permite la evaluación de sus características.

De campo: estudia las pacientes en su ambiente hospitalario.

Longitudinal: contempla los mismos elementos en un período prolongado.

Muestral: se toman 188 casos de 3.140 estudiados.

Cualitativa: los resultados se expresan en calidad y no son cuantificables.

De observación: se determina lo que está ocurriendo.

Documental: estudia material tomado de historias clínicas.

Estudio de casos: análisis detallado de los diferentes estados sépticos de acuerdo con la clasificación utilizada en el servicio.

\section{Técnicas de análisis}

De clasificación y registro: 


\section{Clasificación}

- Características generales de las pacientes

- Grado de infección

- Microbiología

- Cirugía

- Complicaciones

- Mortalidad.

Registro: se hizo en cuadros de acuerdo con la clasificación, con los datos obtenidos de las historias clínicas. El tipo de análisis es lógico por cuanto corresponde a una investigación de pocas unidades (188 casos clínicos).

\section{Microbiología}

Sobre un total de 800 cultivos de material infectado obtenido por escobillonaje de cavidad uterina, por punción del fondo de saco de Douglas, laparotomía o hemocultivos seriados, se estableció que en el servicio los gérmenes aerobios aislados, en orden de frecuencia, son: E. Coli, Estreptococo Beta Hemolítico, Klebsiella Aerobacter, Proteus, Pseudomona y Estafilococo Dorado Coagulasa + .

En anaerobiosis se obtuvieron Estreptococo Beta Hemolítico, E. Coli, Bacteroides, Klebsiella Aerobacter, Proteus, Estafilococo Dorado Coagulasa $+y$ Clostridium Welchi.

Podemos observar que solamente los Bacteroides y los Clostridium son exclusivamente anaerobios y que los demás gérmenes lo son facultativamente (Cuadros Nos. 3 y № 4).

\section{CUADRO Nㅜ 3}

\section{Gérmenes Aerobios}

\begin{tabular}{lr}
\hline Escherichia Coli & $93 \%$ \\
Estreptococo B. Hemolítico & $25 \%$ \\
Klebsiella Aerobacter & $21 \%$ \\
Proteus Mirabilis & $7 \%$ \\
Estafilococo D. Coagulasa + & $4 \%$ \\
Pseudomona Aureoginosa & $3 \%$ \\
\hline
\end{tabular}

\section{CUADRO $N: 4$}

\section{Gérmenes Anaerobios}

\begin{tabular}{lr}
\hline Esteptococo B. Hemolítico & $\mathbf{5 5 \%}$ \\
Escherichia Coli & $19 \%$ \\
Klebsiella Aerobacter & $14 \%$ \\
Bacteroides & $12 \%$ \\
Proteus Mirabilis & $4 \%$ \\
Pseudomona Aureoginosa & $1 \%$ \\
Estafilococo D. Coagulasa + & $1 \%$ \\
Clostridium & $1 \%$ \\
\hline
\end{tabular}

En el $90 \%$ de los casos la infección es producida por asociaciones de Estreptococo Beta Hemolítico, E. Coli, Bacteroides, Klebsiella y Proteus. En 5\% por un solo tipo de germen, frecuentemente Estreptococo o E. Coli. En 2\% por asociaciones de uno o varios gérmenes de los anteriores y Pseudomona Aureoginosa; también $2 \%$ en otras en las cuales se encuentra Estafilococo Coagulasa + , posiblemente productor de penicilinasa. En el $1 \%$ asociaciones con gérmenes anaerobios del grupo de los Clostridium (Cuadro $\mathrm{N}$ : 5).

Estos hallazgos son de gran utilidad en la elección del antibiótico.

\section{Antibiotecoterapia}

Para establecer un criterio en el manejo de los antibióticos fijamos los siguientes principios:
A. Clasificación clínica en cuatro grupos
B. Elección del antibiótico
C. Vía de administración
D. Período de prueba
E. Terapia con antibióticos. Duración
F. No utilizamos asociaciones.

\section{A. Clasificación clínica en cuatro grupos}

Primer grupo: antibióticos de amplio espectro de acción inespecífica (cubren gérmenes Gram + y Gram -, a excepción de la Pseudomona Aureoginosa). En este grupo se encuentran: 
CUADRO N: 5

\section{Asociaciones más frecuentes}

$\begin{array}{lr}\text { Estreptococo B. Hemolítico + E. Coli } & 9 \% \\ \text { Estreptococo B. Hemolítico + Klebsiella } & 72 \% \\ \text { Estreptococo B. Hemolítico + Difteroides } & 7 \% \\ \text { E. Coli + Klebsiella + Estreptococo } & 5 \% \\ \text { Estreptococo + Bacteroides } & 3 \% \\ \text { E. Coli + Klebsiella } & 2 \% \\ \text { Estreptococo + Proteus } & 2 \% \\ \text { Estreptococo + Kebsiella + Bacteroides } & 2 \% \\ \text { Pseudomona + Estreptococo + E. Coli } & 2 \% \\ \text { Clostridium + E. Coli } & 1 \%\end{array}$

1. Penicilina cristalina: (27). Antibiótico de pared, preferiblemente en sal sódica; la sal potásica contiene 1.2 meq de potasio por $1.000 \mathrm{U}$, lo cual constituye un problema en las pacientes con insuficiencia renal aguda. Se debe tener en cuenta la acción que este antibiótico tiene sobre los anaerobios del tipo Bacteroides.

2. Ampicilina. Antibiótico de pared celular con acción similar a la penicilina y especificidad por Shigellas y Salmonellas.
3. Cloramfenicol. Interfiere la síntesis de proteínas en el citoplasma alterando los mecanismos de replicación y transcripción del RNA, de acción similar a la de la Ampicilina; además, cubre especificamente anaerobios exclusivos no esporulados (Bacteroides).

4. Kanamicina. Antibiótico del grupo de los aminoglicósidos, actúa en igual forma que el Cloramfenicol y tiene especificidad por Proteus, Mycobacteria y Gonococo.

\section{PRIMER GRUPO}

\section{Amplio espectro acción inespecífica}

\section{Dosificación}

Penicilina cristalina
Ampicilina
Cloramfenicol
Kanamicina

Segundo grupo. Antibióticos de amplio espectro de acción específica (cubren Gérmenes Gram +. Gram - y Pseudomona). Integran este grupo:

1. Gentamicina. Aminoglicósido que interfiere síntesis proteica, con

$$
\begin{array}{r}
30 \text { millones IV } / 24 \mathrm{hr} \\
4-6 \mathrm{~g} \mathrm{IV} / 24 \mathrm{hr} \\
4-6 \mathrm{~g} \mathrm{IV} / 24 \mathrm{hr} \\
1-2 \mathrm{~g} \mathrm{IV} / 24 \mathrm{hr}
\end{array}
$$

acción específica sobre Pseudomona Aureoginosa y Cocos productores de penicilinasa.

2. Colimicina. Del grupo de los polipéptidos, se presenta en suspensión para uso intramuscular y tiene ac- 
ción específica sobre Pseudomona y Colibacilo. Es un antibiótico que tiene acción de lisis a nivel de la membrana celular.

3. Polimixina. Del mismo grupo, acción similar e igual especificidad que el anterior.

4. Carbenicilina. Penicilina semisintética con acción de pared, a altas dosis cubre Pseudomona y productores de penicilinasa.
Tercer grupo. Antibióticos de espectro Gram + de acción inespecífica (cubren gérmenes Gram +, a excepción de los productores de penicilinasa). En él se agrupan las Penicilinas, los Macrólidos y la Rifampicina.

No hacemos mayor referencia a este grupo debido a su poca aplicación en el Servicio, donde la mayoría de las in. fecciones son por asociaciones de gérmenes Gram + y Gram -. Pertenecen a este grupo: penicilinas, eritromicina, lincomicina, rifampicina, clindamicina.

\section{SEGUNDO GRUPO}

\section{Amplic espectro acción específica}

\section{Dosificación}

Gentamicina

Carbenicilina

Colimicina

Polimixina

$\begin{array}{rrr}280 & -320 \mathrm{mg} \mathrm{IV} / 24 \mathrm{hr} \\ 10 & -30 \mathrm{~g} \mathrm{IV} / 24 \mathrm{hr}\end{array}$

$60.000 \mathrm{U} / \mathrm{kg} / 24 \mathrm{hr}$
Cuarto grupo. Antibióticos de espectro Gram + de acción específica (cubren específicamente gérmenes productores de penicilinasa y a dosis altas de 8-12 g actúan sobre gérmenes Gram -).

1. Penicilinas sintéticas. Actúan a nivel de la pared celular. Incluyen Oxacilina, Cloxacilina, Diclozacilina y Meticilina.

2. Cefalosporinas. Actúan a nivel de la pared celular. Para uso parenteral están: Cefalotina, Cefaloridina, Cefazolina y Celapirina (26). Para uso oral: Cefalexina y Cefradina.

\section{CUARTO GRUPO}

\section{Gérmenes Gram + acción específica Dosificación}

\begin{tabular}{ll} 
Oxacilina & $8-12 \mathrm{~g} \mathrm{IV} / 24 \mathrm{hr}$ \\
Cefalosporinas & $8-12 \mathrm{~g} \mathrm{IV} / 24 \mathrm{hr}$ \\
\hline
\end{tabular}

\section{B. Elección del antibiótico}

Se eligen siempre antibióticos del primer grupo teniendo en cuenta la especificidad particular de cada uno de ellos, a excepción de aquellos casos en que presumimos infección por Pseudomonas o productores de penicilinasa, en los cuales se inicia con alguno del segundo o cuarto grupos.

\section{Vía de administración}

Consideramos que debido a la alteración de la absorción tisular y del tubo digestivo, en los casos de infección grave, los antibióticos se deben utilizar inicialmente por vía endovenosa y en dosis fraccionadas, que permiten mantener niveles hemáticos eficaces y evitan las alteraciones por cambios de $\mathrm{Ph}$ y de humedad.

Una vez recuperada la absorción intestinal pasamos a las formas de ad- 
ministración oral, para comodidad del paciente y retiro de catéteres venosos.

\section{Período de prueba}

Damos un período de prueba de 48 horas a la especificidad del antibiótico; antes no realizamos cambios; si la respuesta clínica y paraclínica es favorable continuamos con el antibiótico inicial, así el resultado del cultivo y antibiogra$\mathrm{ma}$ informe inespecificidad hacia el mismo, pues damos más valor al aspecto clínico.

Si después de las 48 horas la respuesta clínica y paraclínica no es favorable procedemos al cambio, con base en el informe del cultivo y antibiograma; si no disponemos de este examen, pasamos a un antibiótico del segundo grupo buscando cubrir la inespecificidad del primero sobre Pseudomona, productores de penicilina y formas resistentes.

\section{E. Duración de la terapia con antibióticos}

Al cabo de 7 a 10 dias suspendemos la administración de antibióticos a las pacientes que no presenten signos de infección aguda; en aquellas en quienes persisten fiebre o signos de infección aguda localizada, los suspendemos por 48 horas con el objeto de detectar problemas de fiebre medicamentosa o suprainfección: también para tomar muestras para cultivo y antibiograma.

Si después de 48 horas persiste cuadro de infección aguda aplicamos un antibiótico de acuerdo con el informe del cultivo o que fundamentalmente cubra gérmenes productores de suprainfección (Gentamicina, Carbenicilina, Cefalosporinas).

En las pacientes con septicemia o "shock" séptico hacemos el cambio de antibiótico en forma inmediata pues la gravedad del cuadro no permite dejarlas 48 horas sin medicamento.

\section{F. No utilizamos asociaciones de antibióticos por varias razones:}

Un efecto de suma haría innecesaria la asociación, pues se lograría buen resultado utilizando solamente uno de ellos.

Un antibiótico puede resultar especifico para el germen causante de la infección y el otro no; este último va a producir formas resistentes por un lado y por otro destruye flora saprofita antagónica de la flora patógena favoreciendo la suprainfección, lo cual contraindica la asociación.

Los antibióticos asociados pueden tener efectos antagónicos neutralizándose mutuamente cuando se utilizan aquellos que actúan sobre estructuras ceulares diferentes: un antibiótico que altere el metabolismo de la pared celular impe. diría la acción de otro que actúe sobre síntesis de proteínas en el citoplasma, en vista de que el germen se comporta como una unidad funcional.

Por último, la asociación de antibióticos contraría el principio de Paul Erlich según el cual el antibiótico ideal debe tener un espectro mínimo que cubra únicamente los gérmenes patógenos $(22-26,28)$.

\section{Clasificación clínica por estados}

Con el objeto de buscar un criterio unificado para el manejo y tratamiento del aborto séptico, que se pudiera aplicar a nivel nacional, teniendo en cuenta la extensión y gravedad del foco séptico, proponemos la siguiente clasificación que incluye además el tratamiento médico y quirúrgico específico para cada estado $(29,30)$.

Mencionamos antes que existen algunos signos y síntomas de infección aguda con datos de laboratorio comunes para la mayoría de los estados, como son fiebre, calofrío, taquicardia, taquisfigmia, polipnea, secreciones malolientes $y$ leucocitosis con neutrofilia $y$ V.S.G. elevada. 


\section{Clasificación clínica del aborto séptico por estados}

ESTADO I
Ia.
Ib.
ESTADO II
Ila.
IIb.
IIc.
ESTADO III
IIla.
IIIb.
ESTADO IV
IVa.
IVb.

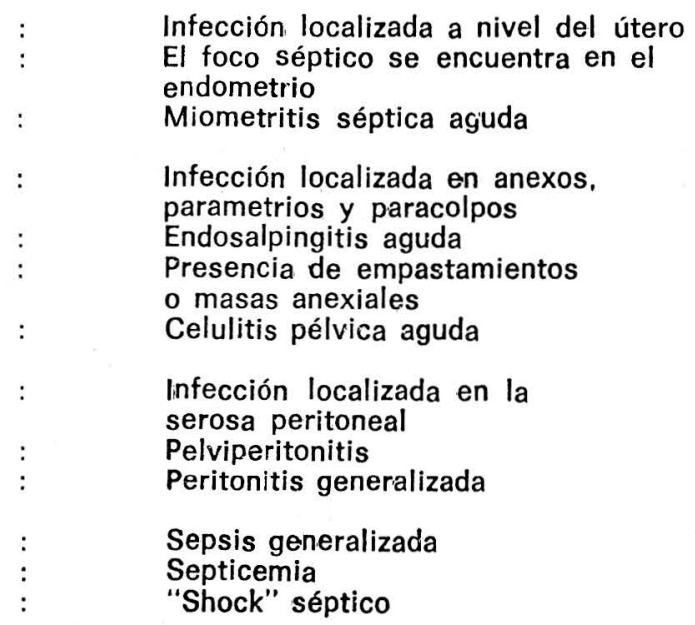

Sepsis generalizada

"Shock" séptico

\section{ESTADO I: Infección localizada a nivel del útero. \\ Estado la. El foco séptico se encuen- tra en el endometrio. Se manifiesta por flujo hemato-purulento acompañado de los signos y síntomas de infección aguda.}

Tratamiento: antibióticos de amplio espectro por vía endovenosa y, dentro de la primera hora de iniciada la antibioticoterapia, raspado uterino previa aplicación de 5 unidades de ocitocina por vía I.V., con el objeto de evitar las perforaciones uterinas. Se recomienda enviar siempre el material obtenido a Patología para descartar lesión séptica del miometrio.

Estado lb. Miometritis séptica aguda.

Se produce por diseminación del foco endometrial por continuidad, ocasiona trombosis de los vasos miometriales, necrosis y formación de microabscesos, que favorecen la generalización del foco séptico.
Clínicamente se caracteriza por la presencia de flujo sanguino-purulento nauseabundo con presencia de membranas verdosas o necróticas y ocasionalmente expulsión de gas a través del conducto cervical. Al tacto vaginal se aprecia intenso dolor a la palpación del fondo uterino, sub-involución que es más evidente en embarazos mayores de 12 semanas, flacidez y ausencia de respuesta a la aplicación de ocitócicos y a la estimulación mecánica de la contracción uterina, como el masaje del fondo uterino y el curetaje.

Es frecuente que se presente sangrado abundante, que puede requerir aplicación de sangre, cuando se practica raspado uterino a estas pacientes. Fácilmente se pueden producir perforaciones uterinas debido a la lesión miometrial. También se observa que el cuello uterino permanece abierto después de 24 horas de evacuado totalmente el citero; lo mismo, el empeoramiento del estado general con facies tóxica, hiperventilación y oliguria. 
Tratamiento: sospechado el cuadro de miometritis séptica aguda se inicia el tratamiento médico a base de antibióticos de amplio espectro y se lleva a la paciente a cirugia para laparotomía, con el fin de confirmar el diagnóstico inicial; éste se comprueba por cambios de coloración del útero, palidez por isquemia, cianosis, hematomas subserosos, flaccidez, ausencia de contractilidad, presencia de infartos hemorrágicos y abscesos miometriales. En estas condiciones se debe practicar histerectomía total abdominal.

En el post-operatorio se deben utilizar sustancias trombolíticas, anticoagulantes $\mathbf{o}$ antiplaquetarios cuando hay trombosis de los vasos ováricos o uterinos para prevenir el tromboembolismo pulmonar. En las primeras 24 horas del post-operatorio se deben vigilar la frecuencia respiratoria y la diuresis, ya que la presencia de hiperventilación y oliguria, se consideran signos premonitorios del "shock" séptico.

ESTADO II: Infección localizada en anexos, parametrios y paracolpos.

Estado Ila. Endosalpingitis aguda producida generalmente por diseminación del foco endometrial por contigüidad.

El cuadro clínico se caracteriza por dolor en el hipogastrio, en ocasiones acompañado de signos de irritación peritoneal (vómito y signo de rebote positivo), con defensa muscular localizada. Al examen ginecológico se encuentran los signos de aborto infectado y al tacto se aprecia cuello doloroso a la movilización e intenso dolor a la palpación de los anexos, sin presencia de masas. El tratamiento inicial es únicamente médico para evitar la exacerbación del foco séptico y la formación de abscesos. Se hace con antibióticos de amplio espectro, antiflogísticos y reposo; una vez controlada la fase aguda, se practica raspado uterino.
Estado Ilb: Empastamientos o masas anexiales producidas por diseminación del foco endometrial por contigüidad.

Se caracteriza el cuadro clínico por dolor en el hipogastrio acompañado de disuria, retención urinaria, dolor a la defecación y constipación por fenómenos de compresión debidos a la presencia de masas en la excavación pélvica.

Al tacto vaginal se comprueba la presencia de masas anexiales que se caracterizan por ser generalmente bilaterales, irregulares, fijas, dolorosas en la fase aguda y de tamaño variable ( 8 a 20 centímetros) que pueden ocupar en forma total o parcial los fondos de saco laterales o el fondo de saco posterior.

Ocasionalmente estas pacientes pueden presentar ictericia localizada en las escleras y signos y síntomas de irritación peritoneal cuando hay inminencia de ruptura del absceso, lo cual implica tratamiento quirúrgico inmediato.

Tratamiento: médico, a base de antibióticos, antiflogísticos y reposo en la fase aguda, en consideración a que un alto porcentaje de estas pacientes evolucionan satisfactoriamente y no necesitan' cirugía.

Controlada la fase aguda, si persiste - aumenta el tamaño de la masa, se procede a la extirpación quirúrgica.

Estado Ilc. Celulitis pélvica. Corresponde a la infección localizada en el paracolpos por diseminación del foco endometrial a través de los linfáticos del cuello, proceso de inflamación difusa con formación de micro-abscesos en su interior, que lesionan las paredes vasculares ocasionando tromboembolismo séptico. La fiebre en "agujas", con facies rubicunda y ocasionalmente dolor en miembros inferiores por fenómenos comprensivos, caracterizan el cuadro clínico de este estado.

Al examen ginecológico deben explorarse cuidadosamente las paredes vagi- 
nales para detectar la presencia de tumoraciones de consistencia pastosa, fijas, irregulares, intensamente dolorosas a la palpación, que dejan fovea a la pre sión, cuyo tamaño fluctúa alrededor de 8 centímetros. El útero y los anexos son de características normales. La lesión es unilateral y el cuadro se caracteriza por la mala respuesta al tratamiento médico.

Tratamiento: médico, a base de antibióticos de amplio espectro, trombolíti$\cos$ y anticoagulantes o antiplaquetarios. Quirúrgico por maceración digital por vía extraperitoneal. Una vez abierta la apeneurosis de los rectos se procede a despegar el peritoneo parietal hasta llegar al parametrio y practicar la maceración digital evitando lesionar vasos uterinos, hipogástricos, femorales y uréteres; se deja un dren a pared abdominal con el objeto de que se organice un absceso encapsulado, para evitar el tromboembolismo pulmonar.

En el post-operatorio se debe continuar la aplicación de trombolíticos, anticoagulantes o antiplaquetarios.

ESTADO III. Infección localizada en la serosa peritoneal.

Estado Illa. Pelviperitonitis, infección localizada en el fondo de saco posterior (31). Se produce por diseminación por contigüidad del foco localizado en las trompas, del cual drena material infectado que por gravedad se deposita en el fondo de saco posterior. Por mecanismo de defensa el epiplón mayor se adhiere al borde superior del ligamento ancho, al fondo uterino y a la pared posterior de la pelvis, aislando la cavidad abdominal y localizando el foco séptico en la excavación pélvica.

El cuadro clínico se caracteriza por dolor en el hipogastrio, disuria, retención urinaria, dolor a la defecación y constipación, siendo esta sintomatología más definida que en el Séptico llb.
A la exploración ảbdominal se aprecian dolor y empastamiento localizados en hipogastrio.

A la especuloscopia se observa rechazo del cuello uterino hacia adelante, quedando en ocasiones oculto debajo del pubis y borramiento del labio posterior por abombamiento del fondo de saco de Douglas.

Al tacto vaginal se encuentra dolor a la movilización del cuello, el cuerpo uterino y los anexos no se pueden precisar por hallarse involucrados en el empastamiento antes descrito. El fondo de saco posterior se encuentra abombado, renitente e intensamente doloroso.

Es indispensable el tacto rectal que permite determinar las características de renitencia, hipertermia y dolor del absceso localizado en el Douglas, Io mismo que la comprensión que éste hace sobre la pared anterior del recto.

Para establecer este diagnóstico es indispensable que esté bloqueada la excavación pélvica y confirmación mediante colpocentesis.

El absceso puede drenar espontáneamente al recto, hecho favorable para la paciente porque evita la colpotomía; la cápsula del absceso posteriormente cierra la fístula rectal.

Tratamiento: antibióticos de amplio espectro, antiflogísticos y reposo; confirmado el diagnóstico por colpocentesis se practica raspado a las pacientes con restos ovulares, seguido de colpotomía; se deja una sonda de Foley durante 4 días.

\section{Estado Illb. Peritonitis generaliza-} da (31).

Se produce por contaminación de la cavidad abdominal a través de focos localizados en endometrio, anexos, o perforación del útero o fondo de saco de Douglas por maniobras abortivas. 
El cuadro clínico se caracteriza por dolor abdominal intenso, acompañado de signos de irritación peritoneal, vómito de color verde pasto, diarrea, distención abdominal por íleo y defensa muscular.

Por constituirse un tercer espacio donde se pierden principalmente agua, sodio y proteínas, estas pacientes presentan deshidratación (que persiste a la administración de líquidos parenterales adecuados) e hipoproteinemia que se manifiesta por edema tisular, apreciable con mayor frecuencia en genitales externos y bases pulmonares. Es frecuente la ictericia en escleras y hay tendencia a la hipotensión. Al examen se encuentran mucosas secas, hipotensión, pulso acelerado, taquicardia, soplos funcionales y reforzamiento del segundo ruido por aumento de la resistencia pulmonar. A la auscultación pulmonar hipoventilación de las bases debido a hipoproteinemia y éxtasis producida por la inmovilidad de los hemidiafragmas.

El abdomen presenta distención, dolor a la palpación superficial y profunda, defensa muscular especialmente localizada hacia los flancos, signo de rebote positivo y alteraciones del peristaltismo intestinal.

El examen ginecológico se caracteriza por lo negativo, ya que no se pueden precisar el útero y los anexos por dolor y defensa muscular; los fondos de saco laterales generalmente están libres y ocasionalmente el Douglas puede estar abombado, lo cual no debe confundirse con pelviperitonitis.

El estudio radiológico de tórax muestra elevación del diafragma y atelectasias planas; en las placas de abdomen simple, en posición horizontal se aprecian distensión de asas delgadas y gruesas, engrosamiento de las paredes intestinales y rechazo de las asas hacia el centro debido al material purulento que ocupa las goteras parietocólicas.
En la vertical aparecen niveles líquidos, se pueden encontrar cámaras de neumoperitoneo por rupturas de víscera hueca o infecciones por gérmenes productores de gas.

Laboratorio: en el parcial de orina se aprecian oliguria, coluria que puede llegar al aspecto de "crema de curuba" y bacteriuria. El cuadro hemático muestra leucocitosis, neutrofilia, sedimentación elevada y anemia; química sanguínea: retención nitrogenada por disminución de la filtración glomerular por hipovolemia y destrucción tisular.

lonograma: disminución del sodio por pérdida de éste en tercer espacio. La trasaminasa glutámico oxalacética se encuentra aumentada por destrucción tisular; cuando hay fenómenos de hemólisis se presenta aumento de la bilirrubinemia. Los gases arteriales suelen demostrar acidosis metabólica por alteraciones del metabolismo del bicarbonato.

Tratamiento: Médico: líquidos, sangre para corregir anemia, plasma para corregir hipoproteinemia, antibióticos de amplio espectro y bicarbonato.

Quirúrgico: drenaje de la peritonitis y extirpación del foco séptico.

ESTADO IV: Sepsis generalizada.

Estado IVa: Septicemia, es la diseminación por vía hemática del foco séptico primario o foco de entrada, con siembras a distancia a diferentes tejidos orgánicos (pulmón, periostio, hígado, bazo, corazón, cerebro, riñón y articulaciones).

El cuadro clínico es polimorfo y depende de los órganos afectados. Se caracteriza básicamente por el severo compromiso del estado general de la paciente, marcada desnutrición, anemia, taquicardia, facies tóxica; hay mala res. puesta del retículo-endotelio que se manifiesta por normotermia o hipotermia, 
recuento de blancos normal o leucopenia con fórmula diferencial y sedimentación globular dentro de límites normales.

Es importante hacer rutinariamente E.C.G., a estas pacientes para detectar focos de endocarditis bacteriana. Como es frecuente que el foco primario desaparezca, se hace más difícil el diagnóstico.

Tratamiento: Médico-quirúrgico, de urgencia, dirigido a corregir la deshidratación con administración de líquidos parenterales, la anemia aplicando sangre, la hipopotreinemia con plasma o sangre, y el trastorno metabólico mediante la adición de bicarbonato; aplicación de antibióticos de amplio espectro que cubran gérmenes anaerobios, Pseudomona o productores de Penicilinasa, preferentemente Cloramfenicol, Gentamicina o Carbenicilina, a las dosis usuales; utilización de anticoagulantes, trombolíticos o antiplaquetarios si persiste embolización. Finalmente, la extirpación quirúrgica del foco séptico primario y secundarios accesibles.

Séptico IVb. "Shock" séptico por respuesta inmunológica exagerada a la acción de las toxinas bacterianas $(20,32$, $33,37,38)$, que conduce a trastornos de la perfusión tisular y profundas alteraciones metabólicas y hemodinámicas.

Se caracteriza por ser normovolémico e hipercatabólico y presentar tres fases bien definidas:

Fase I, de vasodilatación, por acción de las quininas $(34,35,36)$. Fase II, de vasoconstricción, por acción de las catecolaminas. Fase III, de encharcamiento, por agotamiento del sistema simpático y acidosis metabólica severa $(39,40)$.

\section{Cuadro clínico}

Fase I: piel caliente y rubicunda o normotérmica ("shock" caliente), ocasionalmente ictericia generalizada.
Tensión arterial baja, presión veneno. sa central baja. Retardo en la velocidad del Ilenamiento capilar (menos de 3 "). Oliguria (400 cc a $800 \mathrm{cc}$ en 24 horas). Hiperventilación.

Fase II:

- Piel pálida y fría

- Ocasionalmente ictericia generalizada

- Tensión arterial normal o alta. Presión venosa central baja

- Velocidad de lleriamiento capilar disminuida

- Disminución del gasto urinario por debajo de $400 \mathrm{cc}$ en 24 horas (anuaria) $(41,42,43)$.

- Hiperventilación y trastornos de conciencia.

\section{Fase III:}

- Piel fría con aéreas de livideces en tronco y extremidades

- Cianosis peribucal y acrocianosis

- Lesiones petequiales, equimosis y hematomas. Sangrado de mucosas (17)

- Tensión arterial baja. Presión venosa central baja; cuando ésta se encuentra elevada es por asociación de "shock" cardiogénico (44).

- Velocidad de Ilenamiento del lecho capilar retardada

- Anuria, hematuria

- Hiperventilación. Cambios de conciencia

- En estados terminales pérdida del 21). control de esfínteres $(16,17,20$,

\section{Parámetros para el diagnóstico}

1. Identificar el foco séptico.

2. Comprobar trastornos hemodinámicos y de perfusión tisular a través de los cambios en la tensión arterial, la presión venosa central mediante cateterismo venoso, la velocidad del llenamiento capilar y el gasto urinario (dejar sonda vesical a permanencia). 
3. Apreciar los trastornos metabólicos mediante gases arteriales y E.C.G.

Tratamiento: se considera una emergencia médico-quirúrgica.

El tratamiento médico busca restable. cer la volemia mediante la aplicación de soluciones no ionizadas (44); mediante la utilización de bloqueadores alfa o estimuladores beta, abrir los esfínteres pre-capilares y restablecer el flujo.

\section{Empleamos en el Servicio:}

a) Corticoides: 6 a $8 \mathrm{~g}$ de Hidrocortisona, otros a dosis equivalentes $(18,45)$. Tienen acción bloqueadora alfa inotropa positiva y estabilizadora de las membranas de los endotelios y lisosomas (46); como por efecto contralateral bloquean el retículo-endotelio deben suspenderse tan pronto la paciente salga del "shock".

b) Cloropromazina: bloqueador simpático, indirectamente bloqueador al$\mathrm{fa}$, de efecto cronotropo negativo. Se elimina por metabolismo hepático y por esta razón en el "shock" hay efecto acumulativo que puede producir alteración de la conciencia que dificulta el manejo del mismo. Se utilizan dosis de $5 \mathbf{m g}$ cada 5 minutos hasta completar $25 \mathrm{mg}$ que se pueden repetir hasta tres veces en el día.

c) Clorhidrato de Dopamina a dosis de 3 a 5 microgr. por $\mathrm{kg}$ de peso por minuto, por vía endovenosa.

d) Estimuladores beta: disminuyen el vasoespasmo, efecto cronotropo positivo. Se utilizan la Orciprenalina o el Isoproterenol a dosis de 0.2 a $0.10 \mathrm{mi}$ $\mathrm{crogr} / \mathrm{kg} / \mathrm{min} / \mathrm{l}$.V.

Se contraindican en el "shock" cardiogénico.

-Bicarbonato: cuya dosis se calcula de acuerdo con la siguiente fórmula: base exceso $\times$ peso $\times 0.3=$ meq. de bicarbonato para aplicar en dosis única por vía endovenosa.

Cuando no se dispone de gases arteriales se pueden aplicar 1-2 meq. por $\mathrm{kg}$ de peso.

-Antitrombínicos: utilizamos la $\mathrm{He}$ parina para prevenir o tratar la coagulación intravascular diseminada en dosis de 100 unidades por $\mathrm{kg}$ de peso I. V. cada 4 horas, o $1.000 \mathrm{U}$. endovenosas cada hora en 24 horas, o 20.000 a $30.000 \mathrm{U}$. en goteo para 24 horas; hasta cuando se normalicen el fibrinógeno, el tiempo de protrombina y desaparezcan productos de degradación de la fibrina.

Cuando no existe laboratorio se aplica durante 3 a 4 días, tiempo en el cual se supone debe desaparecer la fibrinolisis (47).

-Diuréticos: del tipo de los saluréticos en dosis de 100 a $200 \mathrm{mg}$ de Furosemida o Acido Etacrínico por vía endovenosa. Se puede repetir la dosis hasta completar $1 \mathrm{~g}$ en las 24 horas teniendo en cuenta sus efectos tóxicos de vómito, diarrea, desequilibrio hidroelectrolítico, tinitus y vértigo (48).

-Cloruro de calcio: en dosis de $2 \mathrm{~g}$ en 24 horas con el objeto de controlar hipocalcemia por acidosis metabólica e intoxicación miocárdica por hiperpotasemia.

-Digitálicos: su empleo está limitado al tratamiento del "shock" cardiogénico o de insuficiencia cardíaca congestiva.

-Antibióticos: se deben elegir aquellos que no tengan efecto nefrotóxico y preferiblemente de acción bacteriostática.

Se recomienda el Cloramfenicol en dosis de 4 a $6 \mathrm{~g}$ al día por vía endovenosa; la Penicilina Cristalina en sal sódica, en dosis de 20 a 30 millones en 
las 24 horas, teniendo en cuenta el efecto acumulativo de las dosis por bloqueo de la filtración glomerular.

-Tratamiento quirúrgico: obtenida una respuesta favorable al tratamiento médico se procede a la extirpación del foco séptico, procurando en las pacientes jóvenes conservar un ovario.

Constituye el mejor tratamiento para la infección y el único método para controlar la liberación de toxinas bacterianas.

\section{Laboratorio}

-Parcial de orina: disminución de la diuresis a menos de $400 \mathrm{cc}$ en 24 horas. Isostenuria en la fase anúrica de la insuficiencia renal aguda e hipostenuria en la fase poliúrica. Cuando hay ictericia severa y sangrado por mucosas se aprecia hemoglobinuria y hematuria.

En el examen histológico del sedimen. to urinario se pueden observar células tubulares cuando existe lesión a este nivel.

-Cuadro hemático: leucocitosis, neutrofilia y sedimentación elevada; cuando hay bloqueo del retículo-endotelio se altera muy poco.

-Química sanguínea: nitrógeno ureico y creatinina elevados por hipercatabolismo proteico, mayor destrucción celular y disminución del filtrado glomerular.

-lonograma: hipocalcemia por acidosis metabólica. Hiperpotasemia por mayor destrucción celular, acidosis metabólica y disminución del gasto renal. lica.

-Gases arteriales: acidosis metabó-

-Trasaminasas: elevadas, especialmente la Oxaloacética, por destrucción tisular.
-Bilirrubinemia: Aumentada a expensas de la directa y de la indirecta por edema de los colangiolos, lesión de la célula hepática por anoxia y hemólisis severa.

-Patrón de hemostasis: trombocitopenia por debajo de 140.000 , fibrinógeno inferior a $140 \mathrm{mg}$ y tiempo de protrombina superior a 17 segundos. En es. tas condiciones se considera establecido el síndrome de coagulación intravascular diseminada.

Cuando uno o dos de estos tres elementos no se encuentran alterados, hay necesidad de demostrar la presencia de productos de degradación de la fibrina mediante prueba del sulfato de protamina, entre otros.

-E.C.G.: signos de anoxia miocárdica y de hiper o hipopotasemia. También se pueden observar signos de endocarditis bacteriana.

\section{ANALISIS DE RESULTADOS}

\section{Movimiento en el IMI entre 1970 a 1978}

En el cuadro № 6 se muestran los ingresos en los 9 años; en el anexo $\mathrm{N}$ : 1 , detalladamente, los datos en el período en mención.

CUADRO N: 6

Promedio ingresos al IMI por año

\begin{tabular}{lrrr}
\hline & Total & Promedio & $\%$ \\
\hline Ingresos & 303.883 & 33.764 & - \\
Partos & 215.165 & 23.907 & 71.0 \\
Nacidos vivos & 213.158 & 23.684 & - \\
Abortos & 54.705 & 6.078 & 18.0 \\
Cesáreas & 11.265 & 1.251 & 3.7 \\
Ginecología & 5.577 & 620 & 1.8 \\
Sépticas & 3.140 & 348 & 1.0 \\
Defunciones & 592 & 66 & 0.2 \\
\hline
\end{tabular}


ANEXO № 1

MOVIMIENTO INSTITUTO MATERNO-INFANTIL 1970-1978

\begin{tabular}{|c|c|c|c|c|c|c|c|c|c|c|}
\hline & 1970 & 1971 & 1972 & 1973 & 1974 & 1975 & 1976 & 1977 & 1978 & Total \\
\hline Ingresos & 30.966 & 32.682 & 34.975 & 35.484 & 37.471 & $36.5 \overline{9} 0 \overline{0}$ & 36.666 & 30.777 & 31.373 & 303.883 \\
\hline Partos & 22.345 & 24.018 & 25.092 & 26.272 & 26.533 & 24.432 & 23.190 & 21.341 & 21.942 & 215.165 \\
\hline Nacidos vivos & 22.159 & 23.744 & 24.838 & 25.749 & 26.315 & 24.207 & 23.075 & 21.276 & 21.795 & 213.158 \\
\hline Abortos & 6.266 & 6.569 & 6.363 & 6.561 & 5.948 & 6.501 & 5.460 & 5.403 & 5.634 & 54.705 \\
\hline Cesáreas & 960 & 1.130 & 1.077 & 1.078 & 1.172 & 1.206 & 1.088 & 1.189 & 1.436 & 11.265 \\
\hline Ginecología & 679 & 653 & 749 & 723 & 766 & 515 & 320 & 540 & 632 & 5.577 \\
\hline Ingresos sépticas & 352 & 359 & 378 & 355 & 332 & 363 & 334 & 330 & 336 & 3.140 \\
\hline Detunciones & 64 & 62 & 64 & 88 & 82 & 89 & 61 & 81 & 41 & 592 \\
\hline
\end{tabular}

ANEXO N:2

MOVIMIENTO SERVICIO DE SEPTICAS 1970-1978

\begin{tabular}{|c|c|c|c|c|c|c|c|c|c|c|}
\hline & 1970 & 1971 & 1972 & 1973 & 1974 & 1975 & 1976 & 1977 & 1978 & Total \\
\hline Ingresos & 352 & 359 & 378 & 355 & 332 & 363 & 334 & 330 & 336 & 3.140 \\
\hline Abortos & 242 & 272 & 273 & 248 & 211 & 283 & 222 & 188 & 181 & 2.140 \\
\hline Puerpereas & 44 & 27 & 40 & 41 & 39 & 39 & 50 & 32 & 44 & 356 \\
\hline Cesáreas & 24 & 13 & 11 & 16 & 23 & 28 & 25 & 41 & 60 & 241 \\
\hline Ginecología & 5 & 7 & 13 & 8 & 11 & 5 & 13 & 14 & 14 & $\begin{array}{r}241 \\
90\end{array}$ \\
\hline Heingresos & 8 & 10 & 5 & 7 & 5 & 8 & 5 & 21 & 11 & 80 \\
\hline No sep. gin. ob. & 25 & 30 & 36 & 35 & 37 & 30 & 25 & 34 & 32 & 284 \\
\hline Detunciones & 35 & 27 & 28 & 43 & 44 & 56 & 35 & 53 & 27 & 348 \\
\hline
\end{tabular}




\section{Movimiento en el Servicio de Sépticas en 9 años}

El promedio por año se muestra detalladamente en el anexo No. 2. (Cuadro No. 7).

\section{CUADRO № 7}

Promedio ingresos por años en el servicio

\begin{tabular}{lrrr}
\hline & Total & Promedio & $\%$ \\
\hline Ingresos & 3.140 & 348 & - \\
Abortos & 2.120 & 235 & 67.4 \\
Puérperas & 356 & 40 & 11.2 \\
Cesáreas & 241 & 27 & 7.6 \\
Ginecologia & 90 & 10 & 2.8 \\
Defunciones & 348 & 39 & 11.0 \\
\hline
\end{tabular}

En resumen:

a) El $1 \%$ de los ingresos totales al IMI corresponde a las pacientes manejadas en el Servicio de Sépticas y tal como se aprecia en la gráfica $\mathrm{N}$ 1 , esta relación permanece constante durante los 9 años.

b) El $3.8 \%$ de los abortos que ingresan al IMI presentan complicaciones graves que requieren tratamiento en el Servicio. Esta relación también permanece constante e indica que las condiciones en que se practica el aborto en nuestro medio no han variado en el curso de los 9 años (Gráfica N2).

c) El $0.15 \%$ de las puérperas, $2.1 \%$ de las cesáreas y $1.6 \%$ de las pacientes ginecológicas con infección, fueron tratadas en Sépticas.

\section{Mortalidad en el IMI en 9 años}

El $59 \%$ de la mortalidad general se debió a la sepsis, pues del total de 592, 348 fallecieron por esta causa; en la gráfica $\mathrm{N}$ : 3 podemos apreciar cómo

Gráfica No. 1

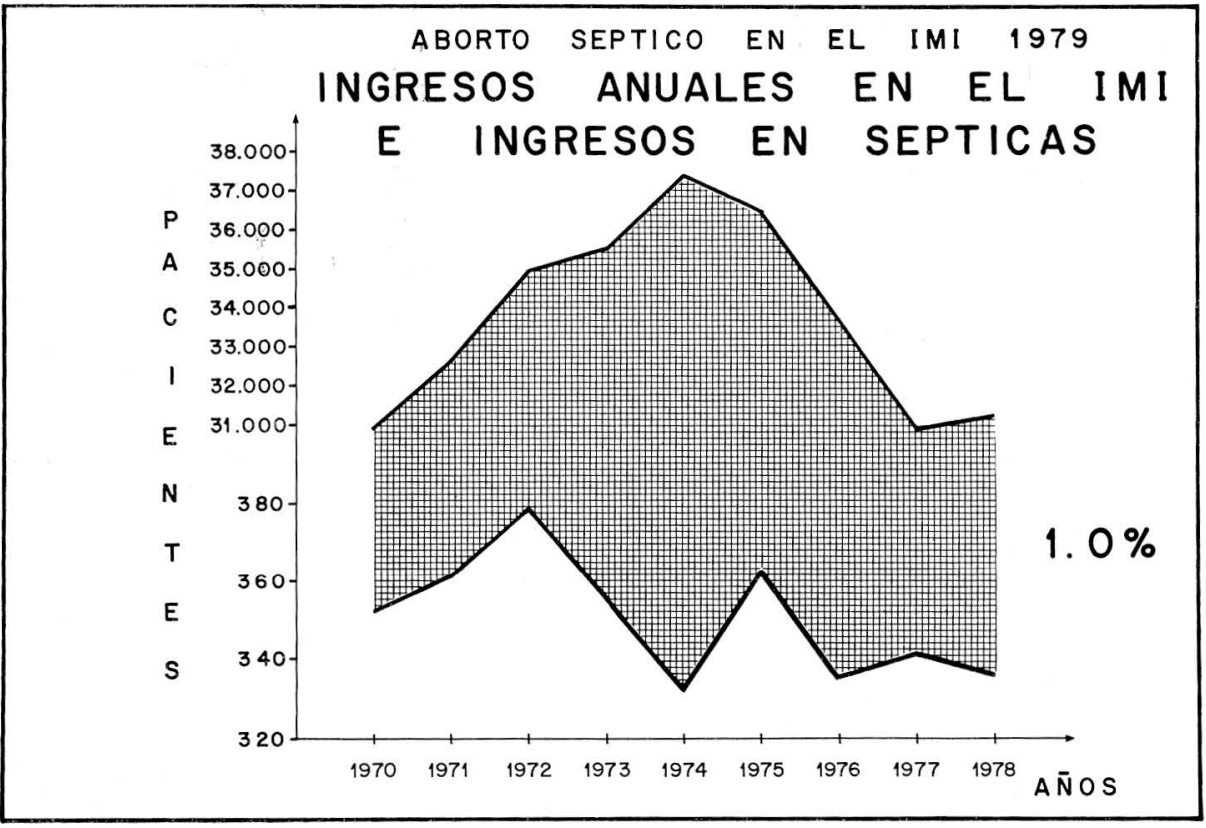


Gráfica No. 2

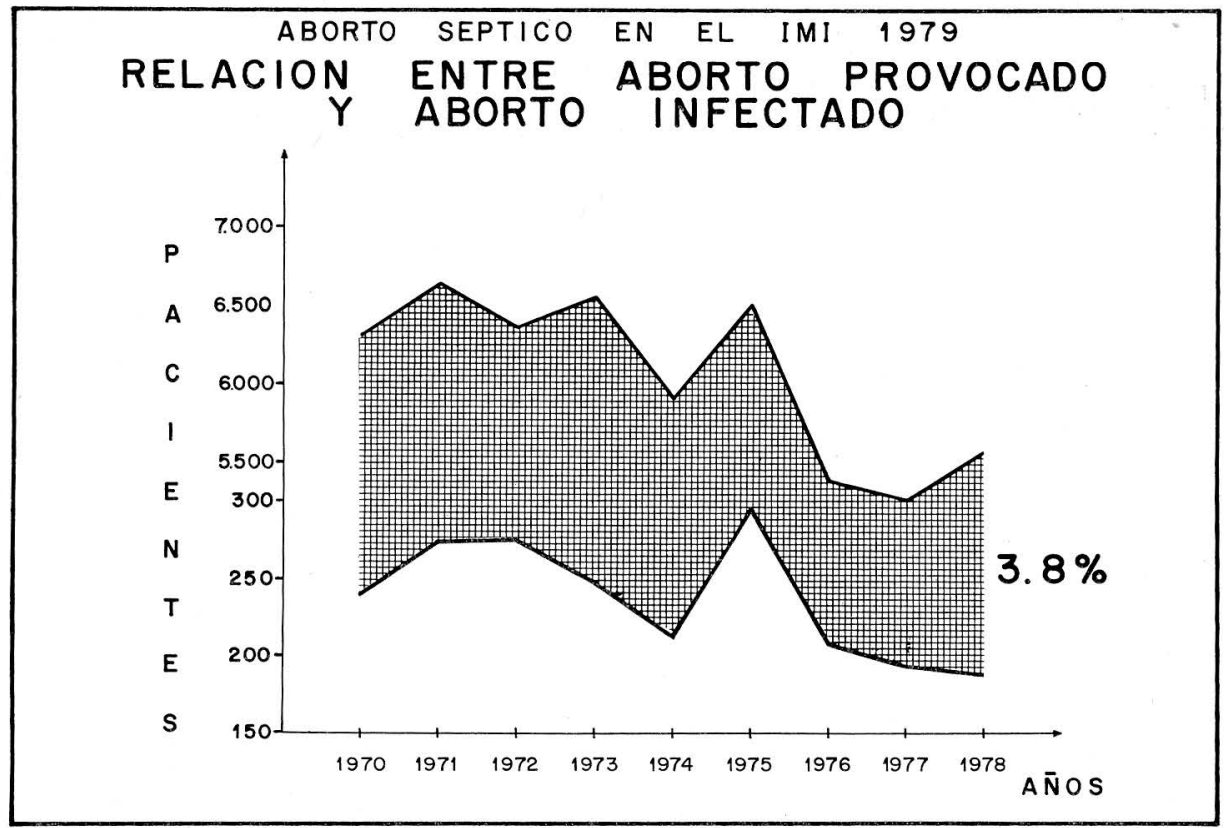

el $40.3 \%$ de la mortalidad por sepsis corresponde al aborto infectado y cómo éste continúa ocupando el primer lugar como causa de muerte en el Instituto, lo cual concuerda con los datos de otros informes locales $(1,2,3)$.

\section{Tasa de mortalidad materna}

Basados en el total de fallecimientos por 10.000 nacidos vivos, tenemos que en 9 años la tasa de mortalidad materna es del $26.5 \%$.

5. Indice de mortalidad por aborto infectado en el Servicio, en 9 años

De las 2.120 pacientes con aborto infectado fallecieron 246 , con un promedio de 29 muertes por año que equivale al $10.4 \%$.

En la gráfica № 4 se observan los índices por año, con una tendencia a la disminución a partir de 1976, fecha en la cual se comenzó a trabajar en el Servicio con la Clasificación Clínica que presentamos en este trabajo. Como comentario adicional anotamos que en relación con el total de abortos que ingresan por año al IMI, la mortalidad es en promedio del $0.47 \%$.

\section{Ingresos en el Servicio de Sépticas en 1977}

En este año se atendieron en el Servicio 330 pacientes, que corresponden al $1 \%$ de los ingresos totales al IMI; 188 de las 330 , es decir el $57 \%$, fueron por aborto y el porcentaje restante involucra a las puérperas, cesáreas, ginecológicas, reingresos y un grupo de pacientes que aunque no presentaban infección ginecobstétricas, fueron tratadas en el Servicio (Gráfica № 5). 


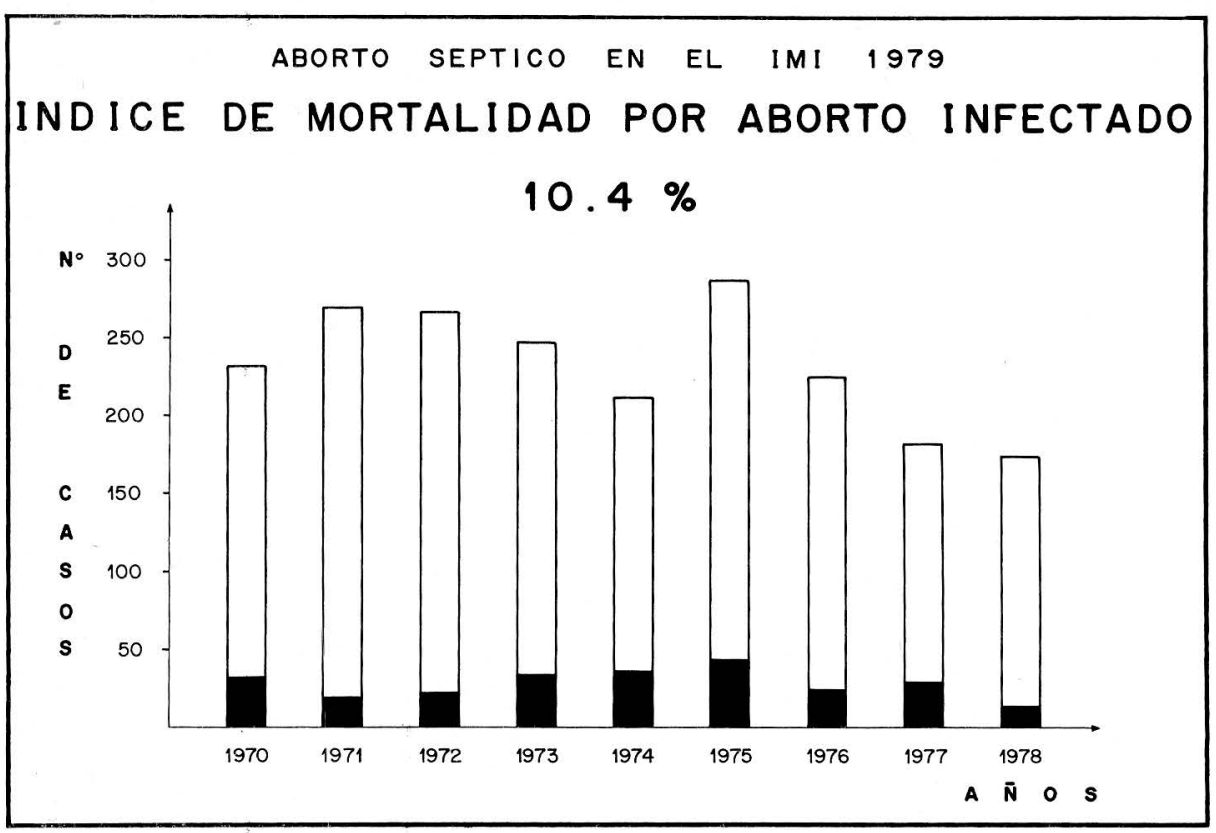

Gráfica No. 4

ABORTO SEPTICO EN EL IMI 1979 MORTALIDAD EN EL IMI EN 9 AÑOS

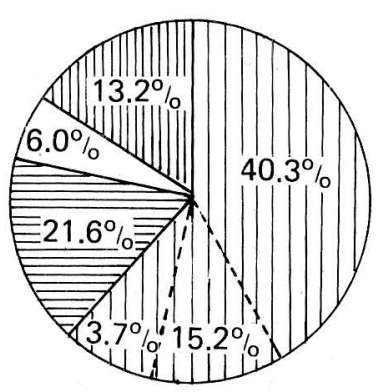
SEPSIS $\left\{\begin{array}{lr}\text { ABORTOS } & 40.3 \% \\ \text { PUERPERAS } & 15.2 \% \\ \text { GINECOLOGIA } & 3.7 \%\end{array}\right.$

\begin{tabular}{|c|c|c|}
\hline 白 & TOXEMIAS & $21.6 \%$ \\
\hline 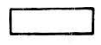 & HEMORRAG & $6.0^{\circ}$ \\
\hline (1010m & OTRAS & $13.2^{\circ}$ \\
\hline
\end{tabular}


Gráfica No. 5

ABORTO SEPTICO EN EL IMI 1979

INGRESOS A SEPTICAS EN 1977 (330)

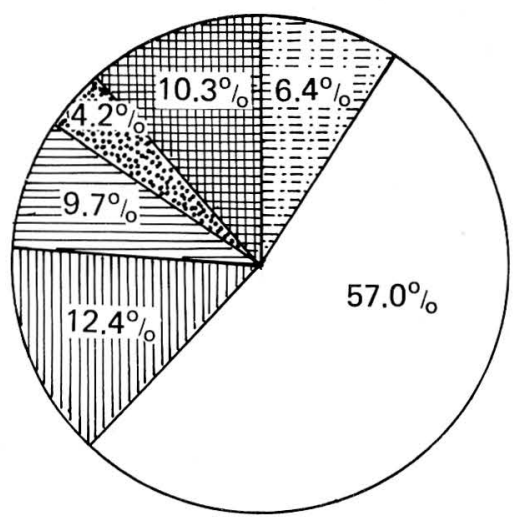

\begin{tabular}{|c|c|c|}
\hline & ABORTOS & \\
\hline ШШ & CESAREAS & \\
\hline & PUERPERAS & \\
\hline Go & GINECOLOGIA & \\
\hline 眏曲曲 & NO SEPTICAS & \\
\hline$\Xi: \Xi::$ & REINGRESOS & \\
\hline
\end{tabular}

\section{Grupo de edad}

El $72.1 \%$ (136) de las pacientes se encuentran entre los 20 a 35 años, cifra similar a la encontrada por Santamaría en 1967 y que corresponde a la que habitualmente se encuentra en los servicios de obstetricia.

El $21.4 \%$ son pacientes mayores de 35 años y un porcentaje inferior es para menores de 19 años (Cuadro $N$ ํ 8).

\section{CUADRO N $N 8$}

\section{Grupos de edad}

\begin{tabular}{lcr}
\hline & No casos & $\%$ \\
\hline Menos de 14 & - & - \\
$15-19$ & 12 & 6.5 \\
$20-24$ & 56 & 29.5 \\
$25-29$ & 48 & 25.5 \\
$30-34$ & 32 & 17.1 \\
$35-39$ & 30 & 16.0 \\
$40-44$ & 10 & 5.4 \\
\hline Total & 188 & 100.0 \\
\hline
\end{tabular}

\section{Paridad}

108 pacientes $(57.6 \%)$ tenían más de 4 embarazos; solamente $22(11.7 \%)$ son primigrávidas; nuevamente se observa semejanza con el estudio de Santamaría, en el que el aborto es más frecuente en multíparas (Cuadro $N$ ㅇ 9).

\section{CUADRO N 9}

Paridad

\begin{tabular}{lcc}
\hline & No & $\%$ \\
\hline G 1 & 22 & 11.7 \\
G 2 & 27 & 14.3 \\
G 3 & 31 & 16.4 \\
G 4 & 32 & 17.0 \\
G 5 & 22 & 11.7 \\
G 6 y más & 54 & 28.9 \\
\hline Total & 188 & 100.0 \\
\hline
\end{tabular}

\section{Semanas de gestación}

En cuanto a la edad de gestación observamos que el $85 \%$ (161) de los abor- 
tos se presentaron entre las 5 a 12 semanas. Después de la semana 12 se presenta una marcada disminución en la tendencia a interrumpir el embarazo (Cuadro $\mathrm{N} \div 10$ ).

CUADRO N 10

Semanas de gestación

\begin{tabular}{lrr}
\hline & \multicolumn{1}{c}{$\mathrm{N}^{\circ}$} & \multicolumn{1}{c}{$\%$} \\
\hline Menos de 4 sem. & 2 & 1.1 \\
$5-8$ & 65 & 34.0 \\
$9-12$ & 96 & 51.0 \\
$13-16$ & 17 & 9.5 \\
$17-20$ & 8 & 4.4 \\
\hline Total & 188 & 100.0 \\
\hline
\end{tabular}

\section{Maniobras abortivas}

El $100.0 \%$ de las pacientes tratadas en este servicio informaron maniobras abortivas, la mayoría con sondas y en algunos casos con "cebolla".

\section{Número de abortos provocados}

Un total de 131 pacientes acudieron al aborto por primera vez, Ilama la atención que son muy pocas las que reinciden (Cuadro № 11).

CUADRO № 11

Número de abortos provocados

\begin{tabular}{lrr}
\hline & No & \multicolumn{1}{c}{$\%$} \\
\hline Primero & 131 & 69.6 \\
Segundo & 35 & 18.7 \\
Tercero & 14 & 7.4 \\
Cuarto y más & 8 & 4.3 \\
\hline Total & 188 & 100.0 \\
\hline
\end{tabular}

12. Valores de hematocrito $y$ y proteinemia al ingreso

Es importante anotar cómo un alto porcentaje de las pacientes $(83 \%)$ ingresaron con hematocrito inferior a 35 y más del $50 \%$ con proteinemia inferior a $6 \mathrm{~g}$ hecho que influye significativamente en el pronóstico de estas pacientes. Vale la pena recordar cómo la desnutrición constituye un factor importante en la infección encontrándose en todas las pacientes fallecidas cifras por debajo de $5 \mathrm{~g}$ (Cuadros № 12 y No 13).

CUADRO № 12

Valores de hematocrito

\begin{tabular}{lcr}
\hline & No & $\%$ \\
\hline Menos de 20 & 15 & 8.3 \\
$21-25$ & 26 & 14.4 \\
$26-30$ & 41 & 22.8 \\
$31-35$ & 68 & 37.8 \\
36 y más & 30 & 16.7 \\
\hline Total & 188 & 100.0 \\
\hline
\end{tabular}

CUADRO N $: 13$

Valores de proteinemia

\begin{tabular}{llcc}
\hline & & $N^{\circ}$ & $\%$ \\
\hline Menor de $6 \mathrm{~g}$ & 91 & 50.6 \\
Mayor de 6 & $\mathrm{~g}$ & 89 & 49.4 \\
\hline Total & & 188 & 100.0 \\
\hline
\end{tabular}

\section{Incidencia por estados clínicos}

En orden de frecuencia la peritonitis y la endometritis ocupan el primer lugar, seguidas por los abscesos tuboováricos, la septicemia y el "shock" séptico. Los casos de miometritis y pelviperitonitis tienen menor incidencia, al igual que la endosalpingitis y la celulitis pélvica (Cuadro № 14).

14. Comparación entre el diagnóstico de ingreso al IMI y el diagnóstico de ingreso al Servicio

El hecho de que en el $37.2 \%(70)$ de los casos el diagnóstico al ingreso no 
CUADRO Nํ 14

Incidencia por estados clínicos

\begin{tabular}{lrr}
\hline & $N^{\circ}$ casos & \multicolumn{1}{c}{$\%$} \\
\hline Séptico la & 47 & 25.0 \\
Séptico Ib & 10 & 5.3 \\
Séptico Ila & 7 & 3.7 \\
Séptico IIb & 31 & 16.5 \\
Séptico IIc & 2 & 1.1 \\
Séptico IIla & 12 & 6.4 \\
Séptico IIIb & 50 & 26.6 \\
Séptico IVa & 14 & 7.5 \\
Séptico IVb & 15 & 7.9 \\
\hline Total & 188 & 100.0 \\
\hline
\end{tabular}

fuese correcto se puede explicar por el recargo asistencial en admisión que impide hacer un examen cuidadoso que permita llegar a un diagnóstico correcto (Cuadro $\mathrm{N}^{\circ}$ 15).

\section{Manejo y tratamiento específicos por estados}

-Séptico la: 47 casos.

A todas las pacientes se les practicó raspado uterino y recibieron antibióticos del primer grupo.
Durante el raspado se produjeron 3 perforaciones uterinas que obligaron a laparotomía exploradora; se hicieron 2 histerectomías abdominales totales y una histerorrafia. La Anatomía Patológica en todos los casos confirmó el diagnóstico clínico. Las complicaciones que se presentaron en las pacientes intervenidas fueron una neumonía y un absceso de cúpula vaginal: La permanencia promedio fue de 7 días, no hubo reingresos ni mortalidad (Cuadro № 16).

\section{CUADRO № 16}

Séptico la

-Permanencia: 7 días-

\begin{tabular}{lrr}
\hline & & \multicolumn{1}{c}{$\%$} \\
\hline Raspado uterino & 47 & 100.0 \\
Histerectomía & 2 & 4.3 \\
Histerorrofia & 1 & 2.1 \\
Mortalidad & 0 & 0.0
\end{tabular}

-Séptico lb: 10 casos. En 9 el tratamiento inicial fue raspado uterino, con antibióticos del primer grupo.

Los principales signos para hacer el diagnóstico de miometritis séptica agu-

CUADRO № 15

Diferencias entre el diagnóstico de ingreso al IMI y el diagnóstico de ingreso al Servicio de Sépticas

\begin{tabular}{lccccr}
\hline & Correto & $\%$ & Incorrecto & $\%$ & Total \\
\hline Séptico la & 28 & 58.6 & 19 & 40.4 & 47 \\
Séptico Ib & 1 & 10.0 & 9 & 90.0 & 10 \\
Séptico IIa & 6 & 85.7 & 1 & 14.3 & 7 \\
Séptico IIb & 23 & 74.2 & 8 & 25.8 & 31 \\
Séptico IIc & $\overline{10}$ & -2.3 & 2 & 100.0 & 2 \\
Séptico IIIa & 10 & 2 & 16.7 & 12 \\
Séptico IIIb & 34 & 68.0 & 16 & 32.0 & 50 \\
Séptico IVa & 14 & 28.6 & 10 & 71.4 & 14 \\
Séptico IVb & 12 & 80.0 & 3 & 20.0 & 15 \\
\hline Total & 118 & 62.8 & 70 & 37.2 & 188 \\
\hline
\end{tabular}


da fueron: hemorragia severa (5 casos); mal estado general con subinvolución, dolor y flacidez uterinos (5 casos); perforación uterina (3 casos).

Se practicó histerectomía abdominal en todos los casos; una paciente con diagnóstico de miometritis séptica aguda al ingreso se llevó inmediatamente a cirugía.

En 2 casos $(20 \%)$ se practicó resección del infundíbulo pélvico por trombosis séptica.

Los informes de Anatomía Patológica reportaron endomiometritis séptica aguda en las 10 piezas quirúrgicas, algunas de ellas con trombosis de vasos miometriales y signos de necrosis.

El $90 \%$ ingresaron con leucocitosis, neutrofilia y VSG elevada. Las complicaciones pulmonares fueron las más frecuentes, ya que el $80 \%$ presentaron neumonía. Dos pacientes hicieron tromboembolismo pulmonar y septicemia. Solamente se reintervino un caso para un cierre de evisceración.

La mortalidad fue del $20 \%$; fallecieron en septicemia las 2 pacientes con tromboembolismo pulmonar.

La permanencia promedio fue de 21 días, reingresó una paciente con sintomatología no relacionado con el proceso inicial. (Cuadro No. 17)

\section{-Séptico lla: 7 casos.}

En todas las pacientes la sintomatología se presentó posterior al raspado uterino lo cual determinó el tratamiento médico, con resultados satisfactorios; no se presentaron complicaciones, reingresos ni mortalidad.

También el $90 \%$ ingresaron con leucocitosis, neutrofilia y V.S.G. elevada.

La permanencia promedio para este estado fue de 7 días. (Cuadro No. 18)
CUADRO Nํ 17

Séptico lb

-Permanencia: 21 días-

\begin{tabular}{lcr}
\hline & No casos & $\%$ \\
\hline $\begin{array}{l}\text { Raspados uterinos } \\
\text { Histerectomía }\end{array}$ & 9 & 90.0 \\
$\begin{array}{l}\text { abdominal } \\
\text { Resección inf. }\end{array}$ & 10 & 100.0 \\
pélvico & 2 & 200 \\
Mortalidad & 2 & 20.0 \\
\hline $\begin{array}{l}\text { Neumonía } \\
\text { Tromboembolismo }\end{array}$ & 8 & 80.0 \\
pulmonar & 2 & 20.0 \\
$\begin{array}{l}\text { Septicemia } \\
\text { Evisceración }\end{array}$ & 2 & 20.0 \\
Reingresos & 1 & Caso \\
\hline
\end{tabular}

CUADRO N 18

Séptico Ila

-Permanencia: 7 días-

\begin{tabular}{lcr}
\hline & $N^{\circ}$ casos & $\%$ \\
\hline Tratamiento & & \\
médico & 7 & 10.0 \\
Mortalidad & 0 & 0.0
\end{tabular}

-Séptico Ilb: 31 casos.

La localización del absceso en el anexo derecho $(71 \%)$ fue más frecuente que en el izquierdo $(29 \%)$.

De acuerdo con lo establecido todas recibieron tratamiento médico inicialmente y respondieron favorablemente el $51.6 \%(16)$, a las cuales no hubo necesidad del tratamiento quirúrgico.

El $48.4 \%$ requirió tratamiento quirúrgico, así: 8 salpinguectomias derechas, 5 bilaterales y 2 izquierdas. 
La morbilidad post-operatoria se debió en primera instancia a los abscesos residuales (9), de los cuales el $33 \%$ (3) necesitaron reintervención quirúrgica. Siguen en orden de frecuencia los abscesos de pared (5), neumonías (4), fístulas de bajo gasto (3), septicemia (2) y una ruptura de un absceso.

Además de las reintervenciones para los abscesos residuales se practicaron dos drenajes de peritonitis y un cierre de evisceración. En el $81 \%$ se encontró leucocitosis con neutrofilia y V.S.G. elevada. La Anatomía Patológica confirmó el diagnóstico en todos los casos. Reingresaron 5 pacientes con abscesos residuales. La mortalidad del $6.4 \%$ corresponde a dos pacientes que hicieron peritonitis generalizada y septicemia.

El promedio de permanencia para este grupo fue de 28 días; una paciente quedó embarazada al cabo de un año de haber salido del hospital. (Cuadro No. 19).

\section{CUADRO N 19}

\section{Séptico Ilb}

-Permanencia promedio: 28 días-

\begin{tabular}{lrr}
\hline & & $\%$ \\
\hline $\begin{array}{l}\text { Tratamiento médico } \\
\text { únicamente }\end{array}$ & 16 & 51.6 \\
$\begin{array}{l}\text { Tratamiento } \\
\text { quirúrgico }\end{array}$ & 15 & 48.4 \\
Mortalidad & 2 & 6.4 \\
\hline Complicaciones & & \\
$\begin{array}{l}\text { Abscesos } \\
\text { residuales }\end{array}$ & 9 & 29.0 \\
$\begin{array}{l}\text { Abscesos de } \\
\text { pared }\end{array}$ & 5 & 16.1 \\
$\begin{array}{l}\text { Neumonia } \\
\text { Fistulas de } \\
\text { bajo gasto }\end{array}$ & 4 & 12.9 \\
$\begin{array}{l}\text { Septicemia } \\
\text { Reintervenciones }\end{array}$ & 3 & 9.6 \\
Reingresos & 2 & 6.4 \\
& 6 & 40.0 \\
\hline & 5 & 16.1 \\
\hline
\end{tabular}

\section{-Séptico IIc: 2 casos.}

Dada la baja frecuencia de la celulitis pélvica y el hecho de que en los exámenes ginecológicos no se tiene la precaución de explorar el paracolpos, en los 2 casos el diagnóstico inicial fue equivocado. A una de estas pacientes se le hizo diagnóstico de septicemia y miometritis séptica aguda. La conducta fue practicarle una histerectomía total abdominal, con resultado a la patología de útero sano; como la paciente continuó evolucionando mal se practicó nueva valorización ginecológica encontrándose empastamiento del paracolpo, lo cual permitió hacer el diagnóstico de celulitis pélvica aguda, efectuándose entonces la maceración extraperitoneal y tra. tamiento médico incluyendo trombolíti$\cos$ (Dextranes)

En el otro caso se hizo el diagnóstico correcto más oportunamente y se estableció el tratamiento médico-quirúrgico correspondiente.

La primera paciente se complicó con endocarditis bacteriana, neumonía, flebotrombosis de miembros inferiores $y$ un cuadro siquiátrico con componente orgánico. El informe de Anatomía Patológica fue de linfadenitis pélvica aguda. No hubo mortalidad, ni reingresos.

La leucocitosis, neutrofilia y V.S.G. elevada se presentó en ambos casos.

Promedio de estancia 52 y medio días. (Cuadro No. 20).

\section{CUADRO N 20}

\section{Séptico IIc}

-Permanencia: 52 días-

\begin{tabular}{lc}
\hline & Casos \\
\hline $\begin{array}{lc}\text { Maceración extraperitoneal } \\
\text { Histerectomía }\end{array}$ & 2 \\
total abdominal & 1 \\
Mortalidad & 0
\end{tabular}




\section{-Séptico IIIa: 12 casos.}

Comprobado el diagnóstico de pelviperitonitis por colpocentesis, se procedió al raspado uterino en todos los casos, seguido de colpotomía en 8 pacientes $(66.7 \%)$; las 4 restantes presentaron drenaje espontáneo al recto a su ingreso.

Como en los estados anteriores, el $90 \%$ de las pacientes presentaron leucocitosis, neutrofilia y V.C.G., elevada.

Una de las pacientes presentó una neumonía como complicación del cuadro inicial. No hubo casos de mortalidad y 3 pacientes reingresaron al cabo de un año con embarazo a término, uno de los cuales era gemelar. (Cuadro No. 21).

CUADRO №21

\section{Séptico Illa}

-Permanencia: 14 días-

\begin{tabular}{lrr}
\hline & & \multicolumn{1}{c}{$\%$} \\
\hline Raspado & & \\
uterino & 12 & 100.0 \\
Colpotomía & 8 & 66.7 \\
Mortalidad & 0 & 0.0 \\
\hline
\end{tabular}

-Séptico IIIb: 50 casos.

Se practicó laparotomía en las 50 pacientes y se extirpó el foco séptico así: salpinguectomía unilateral $40 \%$, histerectomía total abdominal $36 \%$ y salpinguectomía bilateral $16 \%$. El resultado de Anatomía Patológica correspondió en estas piezas quirúrgicas a endosalpingitis aguda, abscesos tubo-ováricos y endomiometritis séptica aguda en todos los úteros extirpados. A una paciente con una perforación uterina, en consideración a su edad (17 años) y a que no había tenido hijos, se le practicó histerorrafia; evolucionó sin complicaciones y posteriormente ingresó al IMI con embarazo a término, presentando un parto normal.
El $70 \%$ se complicó con neumonía; los abscesos residuales ocurrieron en el $32 \%$ y de estos los más frecuentes fueron los abscesos pélvicos, 12, seguidos de absceso subfrénico en 5 casos. Las otras complicaciones fueron las fístulas de bajo gasto, 2, e insuficiencia renal aguda 2 .

La complicación más grave de la septicemia que se presentó en 6 casos y causó la mortalidad del $12 \%$ en este grupo.

Se reintervinieron 11 pacientes: para drenaje de peritonitis residual 3; extirpación quirúrgica de abscesos residuales que no respondieron al tratamiento médico, 17; drenaje extraperitoneal de abscesos subfrénicos 4 y 2 cierres de evisceración.

En el $9.0 \%$ de las pacientes se presentó leucocitosis, neutrofilia y V.S.G. elevada.

Cinco pacientes reingresaron con diagnóstico de abscesos residuales y 3 con embarazos a término.

La permanencia promedio para este estado fue de 35 días. (Cuadro No. 22).

\section{-Séptico IVa: 14 casos.}

En el $85.8 \%$ (12) el foco séptico a distancia se localizó en el pulmón, produciendo neumonía; en un caso se localizó en riñón y el otro en las menínges.

Simultáneamente con el tratamiento médico se procedió al tratamiento quirúrgico, realizándose 4 histerectomías totales abdominales, 4 raspados uterinos, 3 salpingooforectomías, se drenaron 3 peritonitis y se extirpó el infundibulo pélvico en 2 casos.

Solamente el $28.5 \%$ presentaba leucocitosis y el $42 \%$ V.S.G. elevada.

El tromboembolismo pulmonar fue la complicación más frecuente, 6 casos; 
CUADRO № 22

\section{Séptico IIlb}

-Permanencia: 35 días-

\begin{tabular}{lrr}
\hline & & $\%$ \\
\hline $\begin{array}{l}\text { Drenaje de } \\
\text { peritonitis }\end{array}$ & 50 & 100.0 \\
$\begin{array}{l}\text { Salpinguectomia } \\
\text { uniobilateral }\end{array}$ & 28 & 56.0 \\
$\begin{array}{l}\text { Histerectomía } \\
\text { total abdominal }\end{array}$ & 18 & 36.0 \\
$\begin{array}{l}\text { Histerorrafia } \\
\text { Mortalidad }\end{array}$ & 1 & 2.0 \\
\hline $\begin{array}{l}\text { Complicaciones } \\
\text { Neumonía }\end{array}$ & 6 & 12.0 \\
$\begin{array}{l}\text { Abscesos } \\
\text { residuales }\end{array}$ & 35 & 70.0 \\
$\begin{array}{l}\text { Septicemia } \\
\text { Fistula de } \\
\text { bajo gasto }\end{array}$ & 17 & 34.0 \\
$\begin{array}{l}\text { Insuficiencia } \\
\text { renal aguda }\end{array}$ & 6 & 12.0 \\
Reingresos & 2 & 4.0 \\
\hline
\end{tabular}

se presentaron además 2 peritonitis residuales, una endocarditis bacteriana, una fístula de bajo gasto y un absceso subfrénico.

Se reintervinieron 2 pacientes para cierre de evisceración y drenaje de peritonitis residual.

Anatomía patológica: reportó endomiometritis necrotizante aguda 4 casos, endometritis en 4 casos y silpingitis aguda en 3 .

El índice de mortalidad fue del $\mathbf{4 2 . 8 \%}$ siendo el tromboembolismo pulmonar la primera causa.

No hubo reingresos y la permanencia promedio fue de 28 días (Cuadro No.23).

-Séptico IVb: 15 casos.

Doce pacientes presentaron respuesta favorable al tratamiento médico establecido, las 3 restantes ingresaron en fase III (fase de encharcamiento) y fa- llecieron a las pocas horas de haberse hospitalizado.

La histerectomía total abdominal se practicó en 8 pacientes, las otras 4 salieron del "shock" y al iniciarse la anestesia murieron.

Los resultados de las piezas quirúrgicas fueron de endomiometritis necrotizante aguda en el $100 \%$.

En el post-operatorio inmediato una paciente presentó cuadro clínico de pulmón de "shock" y otra hemorragia severa de la cúpula que obligó a reintervenirla.

\section{CUADRO N$: 23$}

\section{Séptico IVa}

-Permanencia promedio: 28 días-

\begin{tabular}{lcc}
\hline & Casos & $\%$ \\
\hline $\begin{array}{l}\text { Histerectomía } \\
\text { total abdominal }\end{array}$ & 4 & 28.5 \\
$\begin{array}{l}\text { Raspado } \\
\text { uterino }\end{array}$ & 4 & 28.5 \\
$\begin{array}{l}\text { Drenaje de } \\
\text { peritonitis }\end{array}$ & 3 & 21.4 \\
$\begin{array}{l}\text { Salpingo- } \\
\text { oforectomía }\end{array}$ & 3 & 21.4 \\
$\begin{array}{l}\text { Extirpación } \\
\text { infundibulo } \\
\text { pélvico }\end{array}$ & 2 & 14.2 \\
$\begin{array}{l}\text { Mortalidad } \\
\text { Complicaciones }\end{array}$ & 6 & 42.8 \\
$\begin{array}{l}\text { Tromboembolismo } \\
\text { pulmonar } \\
\text { Endocarditis } \\
\text { bacteriana }\end{array}$ & 6 & 42.8 \\
$\begin{array}{l}\text { Fístula de } \\
\text { bajo gasto } \\
\begin{array}{l}\text { Absceso } \\
\text { subfrénico }\end{array}\end{array}$ & 1 & 7.1 \\
$\begin{array}{l}\text { Focos sépticos } \\
\text { a distancia } \\
\text { (pulmón izq.) }\end{array}$ & 1 & 7.1 \\
\hline \begin{tabular}{l} 
pol \\
\hline
\end{tabular} & 14 & 100.0 \\
\hline
\end{tabular}


En ninguna de las pacientes se reportó leucocitosis ni neutrofilia, la V.S.G. elevada se encontró en el $86.7 \%$, lo cual puede ser debido a la anemia.

Coagulación intravascular diseminada (CID) se comprobó clínica y paraclínicamente en 10 casos $(66.6 \%)$ y el $100 \%$ presentaron insuficiencia renal aguda.

El alto índice de mortalidad encontrado en este estado, $86.6 \%$, incluye 7 de las 13 pacientes fallecidas que tuvieron una permanencia en el Servicio menor de 12 horas, lo cual disminuiría al $40 \%$ la mortalidad por "shock" séptico, siendo inferior a la de la septicemia; esto es lógico si se tiene en cuenta la gravedad, dificultad del tratamiento y evolución a "shock" séptico de esta última.

De estas pacientes 5 se remitieron a Nefrología para tratamiento de la insuficiencia renal aguda.

No hubo reingresos y la permanencia promedio fue de 7 días (Cuadro No. 24).

\section{CUADRO № 24}

\section{Séptico IVb}

-Permanencia promedio: 7 días-

\begin{tabular}{lcr}
\hline & Casos & $\%$ \\
\hline $\begin{array}{l}\text { Resp. favorable } \\
\text { al tratamiento }\end{array}$ & & \\
médico & 12 & 80.0 \\
$\begin{array}{l}\text { Histerectomía } \\
\text { total abdominal }\end{array}$ & 8 & 53.3 \\
\hline $\begin{array}{l}\text { Complicaciones } \\
\text { Pulmón de }\end{array}$ & & \\
"shock" & 1 & \\
$\begin{array}{l}\text { Hemorragia de } \\
\text { cúpula vaginal }\end{array}$ & 1 & \\
$\begin{array}{l}\text { C.I.D. } \\
\text { I.R.A. }\end{array}$ & 10 & 66.6 \\
$\begin{array}{l}\text { Mortalidad total } \\
\text { Mortalidad con }\end{array}$ & 15 & 100.0 \\
permanencia & 13 & 86.6 \\
de 12 horas & & \\
\hline
\end{tabular}

\section{Análisis de los resultados de Ana- tomía Patológica en 96 piezas quirúrgicas}

-Utero: de 43 , en $40(93 \%)$ se encontró endomiometritis séptica aguda, lesión frecuente que puede llevar al "shock" séptico y la septicemia, comprobada en todos los casos de Séptico IVa y IVb.

-Anexos: de las 46 cirugías de anexos, 19 correspondieron a endosalpinbitis aguda; de éstas, 16 fueron intervenidas por peritonitis y 3 por septicemia. Los 27 restantes corresponden a abscesos tubo-ováricos, de los cuales 12 estaban asociados a peritonitis.

Infundíbulo pélvico: se extirparon 5; derechos, por trombosis séptica con lin. fadenitis y formación de abscesos. Dos de estos se encontraron en pacientes con septicemia, 2 en endomiometritis séptica aquda y uno en paciente con "shock" séptico.

-Paracolpos: dos casos de linfadenitis séptica aquda corresponden a pacientes con diagnóstico de celulitis pélvica (Cuadro $\mathrm{N}^{\mathrm{O}}$ 25).

\section{Mortalidad}

Durante el año de 1977 fallecieron en el IMI, 81 pacientes, $53(65.4 \%)$ en el Servicio de Sépticas.

De estas 53 pacientes, 29 corresponden a aborto séptico, 17 puérperas y 7 de cirugía ginecológica (Gráfica № 6).

De 188 pacientes con aborto séptico, murieron el $15.4 \%$; el cuadro $\mathrm{N}^{\circ} 26$ muestra la mortalidad por estado.

La autopsia se practicó en 14 cadáveres $(48.2 \%)$; las razones para que no se realizara en todas las pacientes fallecidas fueron: permanencia menor de 12 horas y traslado a Medicina Legal, 6 casos, negativa de los familiares, 4 casos, exceso de trabajo en Patología y 
CUADRO N: 25

Anatomía patológica en 96 piezas quirúrgicas

\begin{tabular}{|c|c|c|c|c|}
\hline & & & & $\%$ \\
\hline Uteros & 43 & $\begin{array}{l}\text { Endomiometritis } \\
\text { Endometritis } \\
\text { Sano }\end{array}$ & $\begin{array}{r}40 \\
2 \\
1\end{array}$ & $\begin{array}{r}93.0 \\
4.6 \\
2.4\end{array}$ \\
\hline Anexos & 46 & $\begin{array}{l}\text { Abscesos } \\
\text { tubo-ováriccs } \\
\text { Endosalpingitis }\end{array}$ & $\begin{array}{l}27 \\
19\end{array}$ & $\begin{array}{l}58.6 \\
41.4\end{array}$ \\
\hline Infundíbulo pélvico & 5 & $\begin{array}{l}\text { Trombosis } \\
\text { séptica }\end{array}$ & 5 & 100.0 \\
\hline Paracolpos & 2 & $\begin{array}{l}\text { Linfadenitis } \\
\text { aguda }\end{array}$ & 2 & 100.0 \\
\hline
\end{tabular}

Gráfica No. 6

ABORTO SEPTICO EN EL IMI 1979

MORTALIDAD EN SEPTICAS EN 1977 (53)
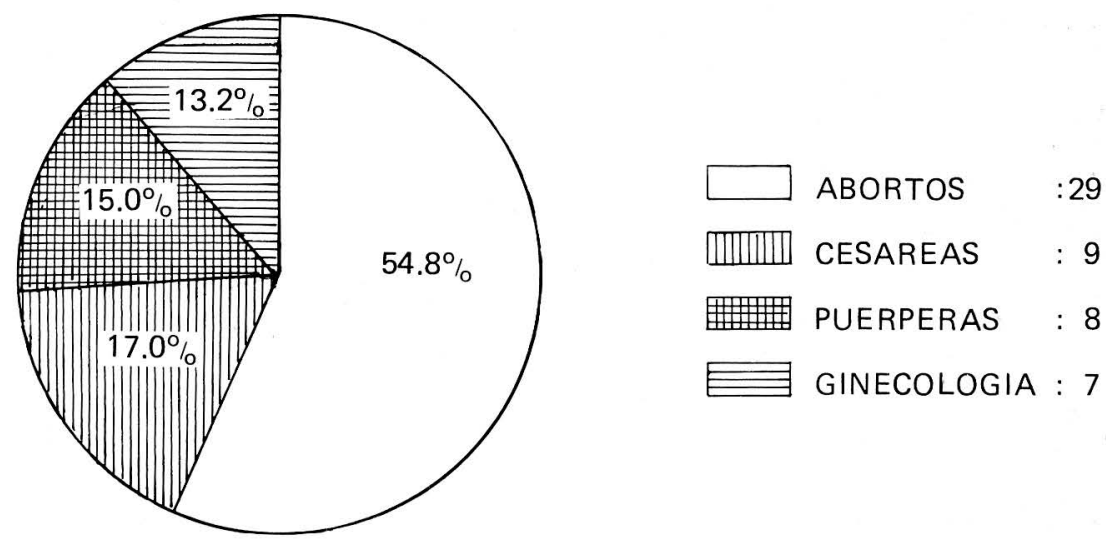
CUADRO N: 26

Mortalidad por estados en 1977

\begin{tabular}{|c|c|c|c|}
\hline & № casos & Defunciones & $\%$ \\
\hline Séptico la & 47 & - & - \\
\hline Séptico lb & 10 & 2 & 20.0 \\
\hline Séptico Ila & 7 & - & - \\
\hline Séptico Ilb & 31 & 2 & 6.4 \\
\hline Séptico Ilc & 2 & - & - \\
\hline Séptico Illa & 12 & - & - \\
\hline Séptico Illb & 50 & 6 & 12.0 \\
\hline Séptico IVa & 14 & 6 & 42.8 \\
\hline Séptico IVb & 15 & 13 & 86.6 \\
\hline
\end{tabular}

causa muy evidente de muerte, 4 casos y cadáver putrefacto, 1 caso.

El resultado de los hallazgos de las necropsias se presenta en el cuadro $\mathrm{N}$. 27 , donde se informa que la septicemia estuvo presente en todos los casos y el órgano más comprometido fue el pulmón.

\section{CUADRO $N: 27$}

\section{4 autopsias (48.2\%)}

\begin{tabular}{lcr}
\hline & & $\%$ \\
\hline $\begin{array}{l}\text { Septicemia } \\
\text { Tromboembolismo }\end{array}$ & 14 & 100.0 \\
pulmonar & 6 & 42.8 \\
$\begin{array}{l}\text { C.I.D. } \\
\begin{array}{l}\text { Peritonitis } \\
\text { generalizada }\end{array}\end{array}$ & 6 & 42.8 \\
$\begin{array}{l}\text { Necrosis } \\
\text { cortical renal }\end{array}$ & 4 & 28.5 \\
$\begin{array}{l}\text { Hemorragia } \\
\text { suprarrenal }\end{array}$ & 2 & 14.2 \\
$\begin{array}{l}\text { Necrosis } \\
\text { tubular }\end{array}$ & 2 & 14.2 \\
\hline
\end{tabular}

\section{CONCLUSIONES}

1. El aborto séptico continúa siendo la primera causa de mortalidad materna.
2. La desnutrición y la anemia son factores que determinan la gravedad de la infección.

3. La flora bacteriana causante de la infección obstétrica, establecida estadísticamente en el Servicio, varía muy poco y nos muestra que el porcentaje de la infección por anaerobios es superior a 90 , debido a la presencia de Bacteroides y Clostridium y gérmenes facultativamente anaerobios.

4. El empleo de un solo antibiótico nos ha permitido valorar la especificidad de dicho antibiótico y prolongar la antibioticoterapia a períodos de 21 a 30 días utilizando solamente tres antibióticos.

La clasificación empleada en el Servicio permite un manejo más racional y ordenado de los mismos.

5. La clasificación clínica por estados facilita el diagnóstico, manejo y tratamiento oportunos del aborto séptico, disminuyendo la mortalidad, ya que el comienzo tardío es un factor negativo definitivo para el pronóstico.

6. La interrupción del embarazo por maniobras abortivas se presentó en pacientes con edad gestacional entre las 5 a 12 semanas en el $85 \%$, coincidiendo con publicaciones anteriores (4, $5,49)$. 
7. En el $100 \%$ de las pacientes de este trabajo existió el antecedente de maniobras abortivas.

8. El $26.6 \%$ de las pacientes tratadas en este año, correspondió al estado séptico IIIb y el $25 \%$ para el la.

9. Los abortós sépticos de estado la, Ila, Ilc y Illa no presentaron mortalidad en esta serie; en tanto que los estados Ib, IVa y IVb presentaron los mayores indices de mortalidad.

10. La miometritis séptica aquda demostró ser un proceso qrave de la infección por causar tromboembolismo séptico y liberación de toxinas bacterianas ,se encontró en el $100 \%$ de los estados Ib, IVa y IVb, Io mismo que en todos los casos de mortalidad.

11. El estado de mayor dificultad para el tratamiento médico-quirúrgico y que presenta mayor morbilidad es el lib, debido a abscesos residuales, fistulas entero-cutáneas y disminución del foco séptico.

12. Los estados la y Illa son los que mejor responden al tratamiento médico-quirúrgico y sorprende el hecho de que el $25 \%$ de las pacientes del IIla quedaron embarazadas posteriormente.

13. El estado séptico IIlb presentó ell mayor promedio de permanencia

(35 días); tiene, al igual que el llb, una alta morbilidad debido a los abscesos residuales, fístulas enterocutáneas, dehiscencia de pared y neumonías por diseminación del foco séptico. Se comprobó que el diagnóstico clínico transoperativo de miometritis séptica aguda fue confirmado por Anatomía Patológica en el $100 \%$ de los casos, constituyendo el mejor método de diagnóstico de esta entidad.

14. El estado séptico IVa presentó un alto índice de mortalidad debido a tromboembolismo pulmonar a partir de miometritis séptica aguda. En este estado fue donde mejor se comprobó que la anemia y la desnutrición eran factores determinantes de la gravedad de la infección.

15. El estado IVb tiene, lo mismo que la septicemia, un alto índice de mortalidad debido al estado avanzado del cuadro en el momento del ingreso. En este estado también se comprobó miometritis séptica aguda en el $100 \%$ de los casos, lo mismo que la insuficiencia renal aguda y coagulación intravascular diseminada en el $66.6 \%$.

16. La mortalidad materna por sépsis en promedio para 9 años es del $59 \%$. De este porcentaje el $40.3 \%$ corresponde al aborto séptico.

17. La mortalidad por aborto séptico en 9 años es del $10.4 \%$.

18. La mortalidad por aborto en el IMI en 19 años es del $0.47 \%$.

19. Se comprobó la diseminación del foco séptico, en primer lugar por contigüidad, en segundo lugar por diseminación hematógena y en tercer lugar por vía linfática.

\section{Resumen}

Presentamos una revisión de 3.140 historias clínicas de pacientes atendidas en el Servicio de Sépticas del IMI de Bogotá, en un período de 9 años.

Se escogen 188 pacientes con aborto séptico tratadas durante el año de 1977 por ser el más representativo del universo en cuestión.

Se presenta una nueva clasificación por estados de aborto séptico, una clasificación clínica para el manejo de antibióticos y un estudio microbiológico de los gérmenes causantes de infección en el Servicio.

En estas 188 pacientes se analizan características generales, grado de infección, manejo, tratamiento quirúrgico y complicaciones. 
El total de pacientes fallecidas es de $29 \mathrm{v}$ se practica necropsia en 14 $(48.2 \%)$.

\section{Morbi-mortality, classification and treatment of septic abortion}

\section{Summary}

We present a review of 3.140 clinical records of patients nursed in Bogotá's IMI Septics Service for a period of nine years.

188 patients with septic abortion, treated during 1977, are chosen because it is the period that best represents the subject under discussion.

A new classification per states of septic abortion is presented, as well as a clinical ranking for the handling of antibiotics and a microbiological study of the germs causing infections in the Service.

The general characteristics, the degree of infection, the management, surgical treatment and complications are all analized in these 188 patients.

The total number of dead patients is $29,14(48.2 \%)$ of which are submitted to post-mortem examination.

\section{Bibliografía}

1. PERALTA CAYON, R. "Mortalidad Materna en el IMI". Tribuna Médica, Año 6, Vol. VI, No 287, 1967.

2. ROJAS L. y cols. "Mortalidad Materna en el IMI". Rev. Col. Obs. Gin. Vol. 25, N:2, p. 127, marzo-abril, 1974.

3. SANCHEZ TORRES, F. "Mortalidad Materna en el IMI". Rev. Col. Obs. Gin. Vol. 18, No 6, p. 217, noviembre-diciembre, 1977.

4. JUBIZ A. y cols. "Mortalidad Materna Comparativa entre dos períodos". Rev. Col. Obs. Gin. Vol. 27, № 3, p. 129, mayo-junio, 1976.
5. MUÑOZ DELGADO, S. "Tratamiento agresivo en el Aborto Séptico". Rev. Col. Obs. Gin. Vol. II, N: 5, p. 487, sep.-oct-, 1960.

6. PERALTA QUINTERO y cols. "Mortalidad Materna en Cuba". Rev. Col. Obs. Gin. Vol. 21, № 5, p. 509, sep.-oct., $197 \mathrm{C}$.

7. PEREZ y cols. “Mortalidad por Infección en el Hospital de Gineco-obstetricia N 3 IMSS". Gin, Obst., Mex.: 29, pp. 483-490, mayo, 1971.

8. WILLIARD CATES y cols. "Legalized abortion: Effect on national trends of Maternal and Abortion-related Mortality 1940 trough 1977". A. J. O. G. Vol. 32, № 2, p. 211, sep. $15,1978$.

9. JAWITZ, E. "Manual de Microbiología Médica". Editorial El Manual Moderno, Méjico, p. 135, 2: edición.

10. GARRIDO, J. "Infecciones Obstétricas". Facultad de Medicina, Universidad de Chile, p. $38,1971$.

11. DOSSETT, J. H. "Defensas Antimicrobianas del Niño y el Hombre". Cli. Ped.. p. 355 , 1972.

12. PLATT, M. "Enfermedades cardíacas, metabólicas, infecciosas en la paciente Obstétrica". Cli. Obs. Gin., p. 196, 1964.

13. NOVAK, J. "Tratado de Ginecología". Nueva Editorial Interamericana, Méjico, 1971, p. 402, 8: edición.

14. Domarus, A. V. "Medicina Interna". Editorial Manuel Marín. Barcelona, 1956.

15. STOSST, T. "Phagocytosis". N. Engl. J. Med. Vol. 290, No 13, 1974.

16. HODES, H. L. "Diagnosis and treatment, Care of the Critically ill child: endotoxin shock". Pediatrics, vol. 44, N:2, 1969.

17. ROBERTS J. M. "Hemorrhagic and endotoxin shock: a pathophysiologic approach to diag. nosis and manegment". A.J.O.G. 119, 1971.

18. BEICHGOTT, M. J. "Deben utilizarse los corticosteroides en el shock". Clin. Med. Norteamérica, sep. 1973.

19. COVANACH, D. "Choque Séptico, choque endotóxico". Cli. Obst., Gin., 219, 1969.

20. LAVIN, J. "Gram negative sepsis: Detection of endotoxe mia with the Limulus test". Ann, Inter, Med. 176: 1, 1972.

21. LILLEHEI, R. C. "La naturaleza del shock irreversible". Traducción del artículo por J. B. Lippincott company. Ann. Surg: 160: 4, 1964. 
22. HERMANS, P. E. "General Principles of Antimicobial therapy". Mayo, Clin., Proc. Vol. 52, pp. 603-610, 1977.

23. CANTOR, H. S. "Suprainfección Microbiana". Clin. Med. Vol. 15, pp. 471-481, marzo, 1971.

24. KAGAN, B. "Antimicrobial Therapy". Editorial W. Saunders. Filadelfia 1974 , p. 3, 2: edición.

25. CARTA MEDICA. "Administración Intravenosa contínua o intermitente de Antibióticos". Edición N: 249 de Medical Letter. Vol. 10. No 15, p. 57, julio, 1968.

26. ANTIBIOTICOS. Monografía. Farma S. A., 1977.

27. WEINSTEIN, L. y cols. "Clinical and bacteriologic studies of effect of massive doses of Penicilin G. on infections caused by gram negative bacilli". New. Englnad J Med. 271: 525-533. Sept. 1, 1964.

28. PLANELLENESS J. y cols. "Efectos nocivos consecutivos al empleo de antibióticos en el tratamiento de las enfermedades infec. ciosas". Ed. Española, Moscú.

29. NEUWIRTH, R. y cols. "Septic Abortion. Changing concept of manegement". A.J.O.G. 85: 24, 1963.

30. GOODNO, A. y cols. "Manegemont of infected abortion". A.J.O.G. 85: 17, enero, 1963.

31. LOZANO CARRILLO, A. "Peritonitis y Pelviperitonitis". Rev. Col. Obs. Gin. 17: 7581. Enero-febrero, 1966.

32. Mc CABE, W. R. "Serum complement leveles in bacteriemic due to gram negative organisms. N. Engl. Med. 288: 23, 1973.

33. MOVAT H. "Mediadores químicos en los fenómenos vasculares de la reacción inflamatoria aguda y de hipersensibilidad inmediata". Cli. Med. Norteamérica, p. 541, 1974.

34. COLMAN, R. W. "Formation of Human Plasma Kinin”. New. Engl. J. Med. 291: 10, 1974.
35. KellermeyeR, R. W. "Kinis. Posible Physiologic and pathologic roles in Man". N Eng. J. Med. 279: 14, 1968.

36. NIES, A. "Contribution of kinins to endotoxin shock in unnasthetixed Rfesus Monkeys". Circulation Res. 22, February, 1968.

37. RUDDY, S. "The complement system of man". N. Engl. J. Med. 287. 189, 1973.

38. KANE, M. A. "Interactions of the classical an alternate complement pathwey with endotoxin lipopolysacharide effect on vlatles and blood coagulation". J. Cin. Znvest, 52: February, 1973

39. ASTRUP, P. "El metabolismo ácido-básico". The Lancet. Saturday 14, 19. 1960. Traducción de Covelli V.

40. ARMSTRONG, M. L. "Electrocardiogramas". Editorial Ateneo Buenos Aires: 1970, pp. $64-$ 76, 1: edición.

41. LUCAS, C. E. "Altered renal hemostasis with acute sepsis". Arch. Surg. 106, 1973.

42. BACK, S. M. "Early prediction of acute renal failure and recovery". Ann. Sur. 177: 3 1973.

43. RAMSAY, A. G. "Insuficiencia Renal Aguda". Clin. Obs. Gin. 219. 1974

44. HARDY, J. D. "Shock and cardiac arrest". Critical Liness. Editorial Saunders company, Filadelfia, 1971, p. 23. 1" edición.

45. DALE, D. E. "Corticosteroides + enfermedades infecciosas". Cli. Med. Norteamérica. Sept. 1973.

46. DEDUVE, C. "Function of Lysosomes". Ann. Rev. Physic. 28: 1966.

47. WAXMAN, B. "Use of heparin in CID". A J. OG. 112: 3. 1972.

48. CARTA MEDICA. Col. 9. № 14. Julio 14 1967.

49. SANTAMARIA, L. Y. y cols. "Aborto Séptico. Maniobras Abortivas". Rev. Col. Obs. Gin. Vol. 18. N: 6. 1967. 